\title{
Sustainability Assessment of Direct Energy Deposition (DED) based Hybrid Manufacturing using Life Cycle Assessment (LCA) Method
}

Faujia Islam

West Virginia University, fi0003@mix.wvu.edu

Follow this and additional works at: https://researchrepository.wvu.edu/etd

Part of the Manufacturing Commons, and the Sustainability Commons

\section{Recommended Citation}

Islam, Faujia, "Sustainability Assessment of Direct Energy Deposition (DED) based Hybrid Manufacturing using Life Cycle Assessment (LCA) Method" (2021). Graduate Theses, Dissertations, and Problem Reports. 8250.

https://researchrepository.wvu.edu/etd/8250

This Thesis is protected by copyright and/or related rights. It has been brought to you by the The Research Repository @ WVU with permission from the rights-holder(s). You are free to use this Thesis in any way that is permitted by the copyright and related rights legislation that applies to your use. For other uses you must obtain permission from the rights-holder(s) directly, unless additional rights are indicated by a Creative Commons license in the record and/ or on the work itself. This Thesis has been accepted for inclusion in WVU Graduate Theses, Dissertations, and Problem Reports collection by an authorized administrator of The Research Repository @ WVU. For more information, please contact researchrepository@mail.wvu.edu. 
Sustainability Assessment of Direct Energy Deposition (DED) based Hybrid Manufacturing using Life Cycle Assessment (LCA) Method

\author{
Faujia Islam
}

Thesis submitted to the

College of Engineering \& Mineral Resources

at West Virginia University

in partial fulfillment of the requirements

for the degree of

Master of Science

in

Industrial Engineering

Zhichao Liu, Ph.D, Chair

Kenneth R. Currie, Ph.D., P.E.

Thorsten Wuest, Ph.D.

Department of Industrial and Management Systems Engineering

\author{
Morgantown, West Virginia
}

2021

Keywords: Life Cycle Assessment, Gabi, DED, CNC, Sustainability

Copyright 2018 [Faujia Islam] 


\begin{abstract}
Sustainability Assessment of Direct Energy Deposition (DED) based Hybrid Manufacturing using Life Cycle Assessment (LCA) Method
\end{abstract}

\title{
Faujia Islam
}

As sustainability has emerged as a highlight for almost every field over the last few decades, the manufacturing field is no exception. Generally, additive manufacturing performs better than traditional manufacturing in terms of sustainability because of its lean energy- and material usage. Previous studies have compared the sustainability performance between traditional and additive manufacturing, but hybrid manufacturing was not focused upon much. In this paper, the life cycle assessment method is used to analyze and compare the energy consumption and environmental impact of direct energy deposition (DED) based hybrid manufacturing and traditional manufacturing "CNC milling" process for a turbine blade.

Six environmental impacts are assessed in this study: global warming potential (GWP), acidification potential (AP), eutrophication potential (EP), ozone depletion potential (ODP), photochemical ozone creation potential (POCP), and abiotic depletion potential (ADP) on the venture to point out the significant issues in the two manufacturing options that impact the environment. Besides, the impact of geometric complexity on the environmental performance for the two processes is also investigated. At lower geometric complexity, the environmental impact of DED and CNC are almost the same. But with the increment of geometrical complexity, DED performs better than $\mathrm{CNC}$ in terms of environmental impact. 


\section{ACKNOWLEDGEMENT}

I would like to wholeheartedly thank my advisor, Dr. Zhichao Liu, for his continued support, guidance, and encouragement during this research work. His support and guidance kept me on track through the countless hours involved in this project and give me the confidence to handle any task given. I would also like to take this time to thank my committee members, Dr. Kenneth Currie and Dr. Thorsten Wuest for their support and guidance in this study.

I wish to extend my thanks to Dr. Bhaskaran Gopalakrishnan and the Industrial Assessment Center (IAC) of Benjamin M. Statler College of Engineering and Mineral Resource for helping me with the energy assessment resource and knowledge.

Lastly, I would like to again thank Dr. Liu, who encouraged me to present a paper on part of this work at the IISE (Institute of Industrial and Systems Engineers) annual conference 2020. 
Table of Contents

1. Introduction $\quad 1$

1.1 Background and Motivation 1

1.2 Statement of the problem: $\quad 4$

1.3 Objective of the research: $\quad 4$

$\begin{array}{lll}1.4 & \text { Challenges: } & 4\end{array}$

2. Literature Review $\quad 5$

2.1 Related Work: $\quad 5$

2.2 Research Gap: 9

3. Methodology: 10

$\begin{array}{lll}3.1 & \text { Life Cycle Assessment: } & 10\end{array}$

3.2 Flow Diagram: 11

3.3 Quantification of Complexity: 13

$\begin{array}{lll}3.4 & \text { Hybrid Manufacturing: } & 15\end{array}$

3.5 Material and Specimen Design: 17

\begin{tabular}{ll}
3.6 & Data Collection: \\
\hline
\end{tabular}

3.6.1 Data Collection Plan: 19

3.6.2 Data Source: 20

3.6.3 Data Collection 22

$\begin{array}{lll}3.6 .4 & \text { Evaluation } & 26\end{array}$

3.7 Life Cycle Impact Assessment 30

3.7.1 Selection and Definition of Impact Categories: 31

$\begin{array}{lll}3.7 .2 & \text { Classification: } & 31\end{array}$

$\begin{array}{lll}\text { 3.7.3 Characterization } & 34\end{array}$

$\begin{array}{lll}3.7 .4 & \text { Normalization } & 39\end{array}$

$\begin{array}{lll}3.7 .5 & \text { Weighting } & 42\end{array}$

4. Result and Discussion 446

5. Conclusion $\quad 49$

$\begin{array}{ll}\text { Reference: } & 51\end{array}$ 


\section{List of Illustrations}

Figure 1: Phases of an LCA (Source: ISO 1997) 11

Figure 2: Detailed process flow diagram for CNC Machining 12

Figure 3: Detailed process flow diagram for DED Machining 12

Figure 4: Cutting tool manufacturing process 13

Figure 5: AMB laser-based Directed Energy Deposition Hybrid System 16

Figure 6: Initial design of turbine blade 17

Figure 7: Trial run with initial blade design 17

Figure 8: Trial run with initial blade design $\quad 18$

Figure 9: Final blade design $\quad 18$

Figure 10: Blade design with different part complexity 19

Figure 11: The user interface of GaBi professional (2021.1) 20

Figure 12: Two processes following the flow diagram $\quad 21$

Figure 13: CNC process flow in GaBi professional $\quad 21$

Figure 14: DED process flow in GaBi professional 22

Figure 15: Experiment using AMBIT laser-based Directed Energy Deposition Hybrid System 23

Figure 16: Connection of data logger with the power source 24

Figure 17: The user interface of HOBOware $\quad 24$

Figure 18: Data visualization of HOBOware 24

Figure 19: Additive manufacturing current consumption trend 25

Figure 20: Subtractive manufacturing current consumption trend 26

Figure 21: Comparison of GWP for two processes

Figure 22: Comparison of ADP for two processes 35

Figure 23: Comparison of AP for two processes

Figure 24: Comparison of EP for two processes 36

Figure 25: Comparison of ODP for two processes 36

Figure 26: Comparison of POCP for two processes

Figure 27: Part Complexity Vs Weighted Environmental Impact Comparison 45

Figure 28: Part Complexity Vs ADP Comparison 46 


\section{List of Tables}

Table 1: Summary of comparison between additive and traditional manufacturing of previous studies

Table 2: Summary of data collection plan of two manufacturing processes

Table 3: Process parameter for Deposition

Table 4: Process parameter for Machining

23

Table 5: Summary of power and material consumption for DED process 26

Table 6: Summary of power and material consumption for CNC process 27

Table 7: Sample computation of geometry parameters and criteria 28

Table 8: Analysis of variance for data sets 28

Table 9: Summary of shape complexity factors 28

Table 10: Characterized value for DED process 33

Table 11: Characterized value for CNC process

Table 12: Normalization factors (Wenzel et al., 1997) 39

Table 13: Normalized value based on experimental data for DED 39

Table 14: Normalized value based on experimental data for CNC 40

Table 15: Normalized value based on estimated data for DED 40

Table 16: Normalized value based on estimated data for CNC 40

Table 17: Weighting factors based on the distance-to-target method (Hauschild and Wenzel, 1998)

Table 18: Weighted value based on experimental data for DED 43

Table 19: Weighted value based on experimental data for DED 43

Table 20: Weighted value based on estimated data for DED 44

Table 21: Weighted value based on estimated data for CNC 44

Table 22: The characterized value of ADP (experimental and estimated) 46 


\section{Introduction}

\subsection{Background and Motivation}

In the ever-changing framework of the manufacturing landscape, the most significant drivers of this change are the exposure of additive manufacturing technology because of its potential cost and resource efficiency in small-scale production. Additive manufacturing (AM) is an advanced technology to fabricate the three-dimensional (3D) parts directly from the 3D computer-aided design (CAD) model. Until the building of the part is completed the materials are deposited layer after layer (Scott et al. 2021). As a result of layer-by-layer fabrication, advantages like highly flexible processes, no requirement of tooling or molds, high efficiency of materials resources, and cost-effectiveness can be achieved by AM (Gasser et al. 2010). Utilizing these competitive advantages, AM has been conveniently applied in the direct fabrication of complex structural components (Jeantette et al. 2000), functionally graded coatings (Pei and De Hosson 2000), and special occasions such as aerospace, defense, biomedical (Santos et al. 2006).

Currently, the manufacturing field is focusing not only on cost-effectiveness but also on sustainability due to natural resource depletion and environmental degradation. The Center for Climate and Energy Solutions (C2ES) stated that in 2015, direct emissions from the industrial and manufacturing sector represented 21.4 percent of the total U.S. greenhouse gas emissions. Direct emissions come from diverse sources and accounted for roughly three-quarters of the sector's total emissions (Morrow et al. 2007).

Therefore, almost all the study of manufacturing is now focusing on two primary targets: sustainability and cost-effectiveness. While cost-effectiveness is relatively easier to gain with optimizing the machining process, achieving sustainability is complex as various factors are related to it. Assessing sustainability needs a lot of factors to be homogenized. Also, different factors impact sustainability differently, therefore, a manufacturing process that is sustainable for one project may not be sustainable for another. Still, from a generalized perspective, additive Manufacturing is considered more sustainable than traditional manufacturing due to its efficient energy and material usage (Liu et al. 2017). The term 'additive manufacturing' covers a broad range of production technologies that fabricate products layer-by-layer, enabling threedimensional objects to be printed on demand. Additive manufacturing (AM) or additive layer manufacturing (ALM) is the industrial production name for 3D printing, a computer-controlled process that creates three-dimensional objects by depositing materials, usually in layers. Using computer-aided design (CAD) or 3D object scanners, additive manufacturing allows for the creation of objects with precise geometric shapes. These are built layer by layer which is in contrast to traditional manufacturing that often requires machining or other techniques to remove surplus material. By ASTM, it is defined as the process of joining materials to make objects from 3D model data, usually layer upon layer, as opposed to subtractive manufacturing methodologies [ASTM (2010) F2792-10e1]. Because of the benefits mentioned below, AM is gaining popularity in the industry: 
- Highly flexible process

- No requirement of tooling or molds

- Savings of material waste and energy

- Prototyping cost much less

- High efficiency of materials resources

- Improved part reliability

Some of the most widely adopted AM technologies are fused deposition modeling (FDM), stereolithography (SLA), direct energy deposition (DED), selective laser melting (SLM), selective laser sintering (SLS), and digital light processing (DLP); but there are a variety of other AM processes too, including polyjet, electron beam melting (EBM), and laminated object manufacture (LOM). In terms of materials, a variety of polymers, metals, ceramics, and composites can be used for AM. The use of these materials is dependent on the type of AM process used (DebRoy et al. 2018). By utilizing only, the amount of material needed for the product, additive manufacturing technologies have the potential to reduce the life cycle material mass and energy consumed relative to conventional subtractive techniques by eliminating scrap, while also eliminating the use of harmful ancillary process enablers. In our experiment, we are going to assess the sustainability of powder-based Direct Energy Deposition (DED) manufacturing processes

Direct energy deposition (DED) is an additive manufacturing process in which focused thermal energy (laser, electron beam, or plasma arc) is used to melt the deposited materials to make dense three-dimensional (3D) structures layer upon layer. By ASTM, DED is defined as an additive manufacturing process in which focused thermal energy is used to fuse materials by melting as they are being deposited [ASTM F3187 - 16]. For the later mentioned advantages, DED is getting competitive advantages over other processes:

- Good metallurgical bonding,

- Controllable heat input,

- Minimal stress and distortion,

- Cost effectiveness for remanufacturing

DED can build complex parts faster and cheaper and, at the same time, generate less waste (Adrita Dass and Atieh Moridi, 2019). Because of the advantages, such as good metallurgical bonding, controllable heat input, minimal stress and distortion, cost-effectiveness for remanufacturing, DED has become a core technology in laser-based remanufacturing. Currently, it is widely applied in high-value components repair, prototyping, and functionally graded material fabrication that meet the demanding requirements from aerospace, defense, automotive, and biomedical industries.

Before going to the problem statement, another vital term of this study should be discussed: sustainability. There is no universally agreed definition of sustainability. There are many different viewpoints on this concept and on how it can be achieved. Sustainability refers to the state of the 
global system in which the needs of the present are met without compromising the ability of future generations to meet their own needs and is continually evolving [ISO_Sustainability_brochure]. There are lots of other definition of sustainability which is accepted both in academia and industry. Another most accepted sustainability definition is by UCLA Sustainability Committee which defines sustainability as "the integration of environmental health, social equity, and economic vitality to living, healthy, diverse and resilient communities for this generation and generations to come."

Nonetheless, nowadays, because of the environmental and social problems societies around the world are facing, sustainability has been increasingly used in a specific way. Nowadays, sustainability is usually defined as the processes and actions through which humankind avoids the depletion of natural resources, to keep an ecological balance that doesn't allow the quality of life of modern societies to decrease.

In this way, the term "sustainability" has been broadly applied to characterize improvements in areas like natural resources overexploitation, manufacturing operations (its energy use and polluting subproducts), the linear consumption of products, the direction of investments, citizen lifestyle, consumer purchasing behaviors, technological developments or business and general institutional changes. As long as an action causes little, less, or no harm to the natural world under the belief (not always ensured) ecosystems will keep on operating and generating the conditions that allow for the quality of life of today's modern societies not to decrease - someone is often claimed to be sustainable.

The principles of sustainability are the foundations of what this concept represents. Therefore, sustainability comprises three pillars: the economy, society, and the environment which are considered as general pillars of sustainability in almost every sector. These principles are also informally used as profit, people, and planet (Hyun-Taek Lee et al, 2019).

In this study, the focus is on the environment by doing a comparative study between two processes. At present days, consumers and citizens are unsatisfied with the long-term damage (both on wealth distribution and the environment) caused by corporate short-sighted focus on short-term profits, which have turned sustainability into a mainstream concept able to ruin a company's reputation and profits if unaddressed. Today, sustainability is often spoken of about climate change, which threatens life as we know it as is being largely caused by industrial practices. That's one of the reasons why today many companies have corporate responsibility (CSR) strategies. 


\subsection{Statement of the problem:}

Some study has been done to find out the environmental benefit of DED additive manufacturing over traditional manufacturing processes for automobile industries. Here in our study, we are going to perform a comparative study between the DED and CNC manufacturing for a turbine blade manufacturing process using Life Cycle Assessment (LCA). If we can distinguish the key factors triggering the environmental impact of these two processes, we can then study how to reduce the impact to make the process more sustainable. The results of this study can help to provide convincing information when judging the environmental benefits of DED over traditional manufacturing. It can also provide an all-sided view about DED and thus help decision-makers making choices in selecting a more sustainable solution.

\subsection{Objective of the research:}

The goal of this study is to quantify and compare the environmental performance of manufacturing a turbine blade by DED and CNC processes. Life Cycle Assessment will be applied to calculate the environmental impacts of these two manufacturing processes. Six environmental impacts are global warming potential (GWP); acidification potential (AP); eutrophication potential (EP); ozone depletion potential (ODP); photochemical ozone creation potential (POCP); and abiotic depletion potential (ADP) are assessed in this study.

\subsection{Challenges:}

The main challenge for this sustainability assessment is where to draw the line of assessment. It took some time to define how far down the chain do we want to identify and quantify the life cycle modeling flow. Building the life cycle model on Gabi was also challenging as random nondescript errors were faced during the building process which was troublesome to solve. It was planned to include the impact of part complexity in the sustainability study but very little literature is available on this topic. During the literature review, it was found that quantifying complexity will be demanding. Another taxing decision was to include tool manufacturing in life cycle modeling. Tool manufacturing is a lengthy process. If we want to do the whole experiment, it will be very large compared to our main flow of experiment. But on the other hand, it will be very interesting to see how it impacts the whole lifecycle as this study was not done before. The detailed life cycle processes, including the materials extraction, transportation, materials production, part fabrication, and post-processing are modeled with the software. 


\section{Literature Review}

\subsection{Related Work:}

A very rich literature is available on the Sustainability Assessment of Direct Energy Deposition (DED) based Hybrid Manufacturing using Life Cycle Assessment (LCA) Method. The State of the Art in Directed Energy Deposition has been discussed by Adrita Dass (2019). In their work, they have covered the range from Additive Manufacturing to Materials Design and they tried to establish the process maps for DED. Their experiment has provided a comprehensive review of the classification of DED systems, process variables, process physics, modeling efforts, common defects, mechanical properties of DED parts, and quality control methods. Their study has proved that there are many far-from-equilibrium and highly dynamic phenomena during DED due to extreme heating and cooling rates which include dynamic melt pool, melting and vaporization of powder particles, rapid solidification, and phase transformation. Daniel Böckin (2019) said that environmental improvements due to AM are consistent with the key indicator like weight reduction potential of AM which results in decreased use phase impacts more than compensating for increased impacts from production. But from a short-term perspective, AM implementation is not beneficial without some technological improvement like scope to manufacture large components and to use low alloy steel as a feedstock.

Simon Ford (2016) has introduced four categories where Additive Manufacturing can provide sustainable benefits over traditional manufacturing in his study. The categories found in this study can be divided into four major clusters: Product and process redesign, material input processing, make-to-order component, and product manufacturing and closing the loop which was decided Using a product life cycle perspective. This study has provided a clear observation on sustainability advantages and challenges of AM adoption in industries which is very beneficial to the industries to decide which manufacturing process to adopt in any specific manufacturing requirement

Tanisha Peraira (2018) has studied the capability of AM and its current development to compete or add to traditional manufacturing regions. The study says that the present models for high production volumes are better suited for traditional manufacturing methods, however, the higher the complexity or customization required AM is better suited. The paper comparison also focused on the similarities, differences, advantages, and disadvantages found in AM vs SM studying the economic, environmental, and quality management status of the industry today. AM offers flexibility, which enables manufacturers to create an optimal design for lean production. AM is found better for single units and very low-volume production in several sectors.

In the older studies, additive manufacturing has been considered more sustainable than traditional manufacturing due to its efficient energy and materials used only for polymer materials, not for metallic materials. Zhichao Liu (2017) has done a comparative study for environmental performances of traditional manufacturing and direct energy deposition processes using the Life cycle assessment process. The final environmental impact shows that the gear laser fabrication (DED) will generate more environmental impact compared with its traditional manufacturing process. The results of GWP, AP, ODP, ADP, and POCP of the gear traditional manufacturing are only $30.33,43.42,17,65.05$, and $54.68 \%$ of that in gear laser fabrication. The results of GWP. AP, 
EP, ODP, and POCP show that the environmental impacts are generated by the electricity production in the gear laser fabrication process.

Qiuhong Jiang (2014) provided the Life Cycle Assessment of an Engine with Input-Output Based Hybrid Analysis Method where he used the Process-based Life Cycle Assessment (P-LCA). This article verifies the effectiveness of the Input-Output based hybrid inventory analysis method with application to the pre-consumer stages of the Chinese engine manufacturing industry. Although the result could not provide specific improvements for specific engine manufacturing technology, it proposes an optional LCI method for analyzing and quantifying the environmental impacts when the target product already exists in the industrial sectors.

Table 1: Summary of comparison between additive and traditional manufacturing of previous studies

\begin{tabular}{|c|c|c|c|c|}
\hline $\begin{array}{l}\text { Additive } \\
\text { Manufacturing }\end{array}$ & $\begin{array}{l}\text { Traditional } \\
\text { Manufacturing }\end{array}$ & Method Used & Major Findings & Reference \\
\hline $\begin{array}{l}\text { Electron Beam } \\
\text { Melting (EBM) } \\
\text { process }\end{array}$ & Milling & $\begin{array}{l}\text { Life Cycle } \\
\text { Assessment } \\
\text { (LCA) using } \\
\text { SIMAPRO }\end{array}$ & $\begin{array}{l}\text { EBM is more } \\
\text { environment-friendly } \\
\text { for parts with shape } \\
\text { complexity. } \\
\text { - Parts with an acceptable } \\
\text { level of complexity for } \\
\text { five axes milling will } \\
\text { generate a lower } \\
\text { environmental impact. }\end{array}$ & $\begin{array}{l}\text { Henri Paris } \\
(2016)\end{array}$ \\
\hline $\begin{array}{l}\text { Powder Bed } \\
\text { Fusion }(\mathrm{PBF})\end{array}$ & $\begin{array}{l}\text { Conventional } \\
\text { Manufacturing }\end{array}$ & $\begin{array}{l}\text { Life Cycle } \\
\text { Assessment } \\
(\mathrm{LCA}) \text { using } \\
\mathrm{GaBi}\end{array}$ & $\begin{array}{l}\text { Environmental } \\
\text { improvements due to } \\
\text { AM are consistent with } \\
\text { the key indicator like } \\
\text { weight reduction } \\
\text { potential of AM. } \\
\text { - From a short-term } \\
\text { perspective, AM is not } \\
\text { beneficial without some } \\
\text { technological } \\
\text { improvement. }\end{array}$ & $\begin{array}{l}\text { Daniel } \\
\text { Böckin } \\
(2019)\end{array}$ \\
\hline
\end{tabular}




\begin{tabular}{|c|c|c|c|c|}
\hline \begin{tabular}{|l|} 
Direct Energy \\
Deposition (DED)
\end{tabular} & & $\begin{array}{l}\text { Life Cycle } \\
\text { Assessment } \\
\text { (LCA) using } \\
\text { GaBi }\end{array}$ & $\begin{array}{l}\text { Remanufacturing by } \\
\text { laser cladding cuts } \\
63.8 \% \text { environmental } \\
\text { impact over the entire } \\
\text { life cycle. } \\
\text { - Remanufacturing will } \\
\text { not be the preferred } \\
\text { option if it needs to } \\
\text { repair more than } 16 \\
\text { cracks. }\end{array}$ & $\begin{array}{l}\text { ZhiChao Liu } \\
\text { (2016) }\end{array}$ \\
\hline $\begin{array}{l}\text { Direct Energy } \\
\text { Deposition (DED) }\end{array}$ & $\begin{array}{l}\text { Conventional } \\
\text { Manufacturing }\end{array}$ & $\begin{array}{l}\text { Life Cycle } \\
\text { Assessment } \\
\text { (LCA) using } \\
\text { GaBi }\end{array}$ & $\begin{array}{l}\text { - Gear laser fabrication } \\
\text { (DED) will generate } \\
\text { more environmental } \\
\text { impact. }\end{array}$ & $\begin{array}{l}\text { ZhiChao Liu } \\
\text { (2017) }\end{array}$ \\
\hline $\begin{array}{l}\text { Additive } \\
\text { Manufacturing }\end{array}$ & $\begin{array}{l}\text { Traditional } \\
\text { Manufacturing }\end{array}$ & \begin{tabular}{|l} 
Theoretical \\
Life Cycle \\
Assessment
\end{tabular} & $\begin{array}{l}\text { Four major categories } \\
\text { are found where AM } \\
\text { can provide sustainable } \\
\text { benefits: Product and } \\
\text { process redesign, } \\
\text { material input } \\
\text { processing, make-to- } \\
\text { order component, and } \\
\text { product manufacturing } \\
\text { and closing the loop. }\end{array}$ & $\begin{array}{l}\text { Simon Ford } \\
(2016)\end{array}$ \\
\hline \begin{tabular}{|l|} 
Direct Energy \\
Deposition (DED)
\end{tabular} & & $\begin{array}{l}\text { Process map } \\
\text { using the } \\
\text { linear heat } \\
\text { input and } \\
\text { powder feed } \\
\text { rate as } \\
\text { variables }\end{array}$ & $\begin{array}{l}\text { A comprehensive } \\
\text { review on the } \\
\text { classification of DED } \\
\text { systems, process } \\
\text { variables, process } \\
\text { physics, modeling } \\
\text { efforts, common } \\
\text { defects, mechanical } \\
\text { properties of DED } \\
\text { parts, and quality } \\
\text { control methods. }\end{array}$ & $\begin{array}{l}\text { Adrita Dass } \\
(2019)\end{array}$ \\
\hline
\end{tabular}




\begin{tabular}{|c|c|c|c|c|}
\hline & $\begin{array}{l}\text { Traditional } \\
\text { Manufacturing of } \\
\text { diesel engine }\end{array}$ & $\begin{array}{l}\text { Life Cycle } \\
\text { Assessment } \\
(\mathrm{LCA}) \text { using } \\
\mathrm{GaBi}\end{array}$ & $\begin{array}{l}\text { - PED, GWP, and POCP } \\
\text { are predominant } \\
\text { impacts along with the } \\
\text { entire diesel engine life }\end{array}$ & $\begin{array}{l}\text { Tao Li } \\
\text { (2013) }\end{array}$ \\
\hline $\begin{array}{l}\text { Direct Additive } \\
\text { Laser } \\
\text { Manufacturing } \\
\text { (CLAD) }\end{array}$ & $\begin{array}{l}\text { Conventional } \\
\text { Manufacturing }\end{array}$ & $\begin{array}{l}\text { Life Cycle } \\
\text { Assessment } \\
\text { (LCA) using } \\
\text { SIMAPRO }\end{array}$ & $\begin{array}{l}\text { - CLAD has } 70 \% \text { less } \\
\text { environmental impact } \\
\text { than conventional } \\
\text { manufacturing }\end{array}$ & $\begin{array}{l}\text { Nicolas } \\
\text { Serres (2011) }\end{array}$ \\
\hline Re-manufacturing & & $\begin{array}{l}\text { Embodied } \\
\text { energy } \\
\text { concept }\end{array}$ & $\begin{array}{l}\text { A case study is } \\
\text { conducted on the } \\
\text { crankshaft of waste } \\
\text { diesel that results in } \\
\text { different energy } \\
\text { consumption values of } \\
\text { different greasy dirt } \\
\text { degrees and wears } \\
\text { degrees of the waste } \\
\text { crankshaft in the } \\
\text { remanufacturing } \\
\text { process. }\end{array}$ & $\begin{array}{l}\text { Tao Li } \\
\text { (2014) }\end{array}$ \\
\hline \begin{tabular}{|l|} 
Additive \\
Manufacturing
\end{tabular} & & \begin{tabular}{|l|} 
Process-based \\
Life Cycle \\
Assessment \\
$($ P-LCA $)$
\end{tabular} & $\begin{array}{l}\text { The result could not } \\
\text { provide specific } \\
\text { improvements for } \\
\text { specific engine } \\
\text { manufacturing } \\
\text { technology. } \\
\text { - It proposes an optional } \\
\text { LCI method for } \\
\text { analyzing and } \\
\text { quantifying the } \\
\text { environmental impacts. }\end{array}$ & $\begin{array}{l}\text { Zhichao Liu } \\
\text { (2014) }\end{array}$ \\
\hline \begin{tabular}{|l|} 
Additive \\
Manufacturing
\end{tabular} & & & $\begin{array}{l}\text { - The structural design of } \\
\text { the machines, } \\
\text { classification, the } \\
\text { alternatives existing } \\
\text { today, materials used } \\
\text { and their } \\
\text { characteristics, the } \\
\text { technology limitations } \\
\text { are discussed here. }\end{array}$ & $\begin{array}{l}\text { Mariano } \\
\text { Jiménez } \\
\text { (2019) }\end{array}$ \\
\hline
\end{tabular}




\begin{tabular}{|c|c|c|c|c|}
\hline $\begin{array}{l}\text { Additive } \\
\text { Manufacturing }\end{array}$ & $\begin{array}{l}\text { Subtractive } \\
\text { Manufacturing }\end{array}$ & & $\begin{array}{l}\text { The higher the } \\
\text { complexity or } \\
\text { customization required } \\
\text { AM is better suited. } \\
\text { AM is better for single } \\
\text { units and very low- } \\
\text { volume production in } \\
\text { several sectors. }\end{array}$ & $\begin{array}{l}\text { Tanisha } \\
\text { Peraira } \\
(2018)\end{array}$ \\
\hline $\begin{array}{l}\text { Direct Metal } \\
\text { Deposition } \\
\text { (DMD) }\end{array}$ & $\mathrm{CNC}$ milling & Case study & $\begin{array}{l}\text { Simple molds with a } \\
\text { high solid-to-cavity } \\
\text { volume ratio and } \\
\text { minimal amounts of } \\
\text { finish machining are } \\
\text { least environmentally } \\
\text { burdensome to produce } \\
\text { via CNC milling, while } \\
\text { molds with a low solid- } \\
\text { to-cavity volume ratio } \\
\text { are least } \\
\text { environmentally } \\
\text { burdensome to produce } \\
\text { via DMD. }\end{array}$ & $\begin{array}{l}\text { W.R. } \\
\text { Morrow } \\
(2007)\end{array}$ \\
\hline
\end{tabular}

\subsection{Research Gap:}

In the past sustainability assessments of Direct Energy Deposition (DED) based Hybrid Manufacturing, they have covered a lot of parameters which are the main factors behind the environmental impact of that certain process. After reviewing the previous works, it was found that they have proposed to study how the volume of lots impacts the environmental emission of traditional and additive manufacturing but none of the existing studies have covered this. Also, the design complexity is playing an important role in the impact, but this field is also yet to study which also includes the shape factor, $\mathrm{k}$.

In the CNC machining process, the cutting tool is used for $\mathrm{CNC}$ milling and finishing. For specific jobs, a certain cutting tool is required to use which involves separate manufacturing. In the previous works, how much energy is required for the cutting tool production is not included in the Life cycle boundary. In our study, we have decided to consider this to find out how it impacts the emission. 
In the remanufacturing process, a defective part can be repaired for reusing instead of manufacturing a new one which should have a different environmental impact. Also, previous studies didn't consider the integrated machine in their experiment. As this technology is available now, so this new case can be considered for further study.

\section{Methodology:}

\subsection{Life Cycle Assessment:}

Life Cycle Assessment (LCA) is a "cradle to grave" approach for assessing the environmental aspects of a product or a process. By including the impacts caused throughout the product life cycle, LCA provides a comprehensive view of the environmental aspects of a product or process and a more accurate picture of environmental trade-offs in product and process selection (Liu et al. 2014). ISO 14040 defines LCA as "compilation and evaluation of the inputs, outputs and the environmental impacts of a product system throughout its entire life-cycle from raw material extraction, manufacturing, and use to ultimate disposal".

Life cycle assessment (LCA) is a useful tool to help improve companies' environmental performances by estimating the cumulative environmental impacts resulting from the entire product life cycle, including the impacts not considered in other traditional analysis methods. LCA method looks at potential impacts on the environment due to the extraction of resources, transportation, production, use, and end-of-life of products. With the potential to provide a comprehensive view of environmental performances, LCA has been successfully used in both academics and industry (Kreiger et al. 2013).

According to the International Organization for Standardization (ISO) 14040 and 14044 standards, an LCA consists of the following four components:

a) Goal and scope definition: Determine the type of information that is needed to add value to the decision-making process.

b) Life cycle inventory (LCI) analysis (LCIA): Quantify energy and raw material requirements, atmospheric emissions, waterborne emissions, solid waste, and other releases for the entire life cycle of a product, process, or activity.

c) Life cycle impact assessment: Assess the potential human and ecological effects of energy, materials usage, and environmental releases, as identified in the inventory analysis.

d) Life cycle interpretation: Identify, quantify, check, and evaluate information from the results of LCI and LCIA and communicate them effectively (ISO 1998). 


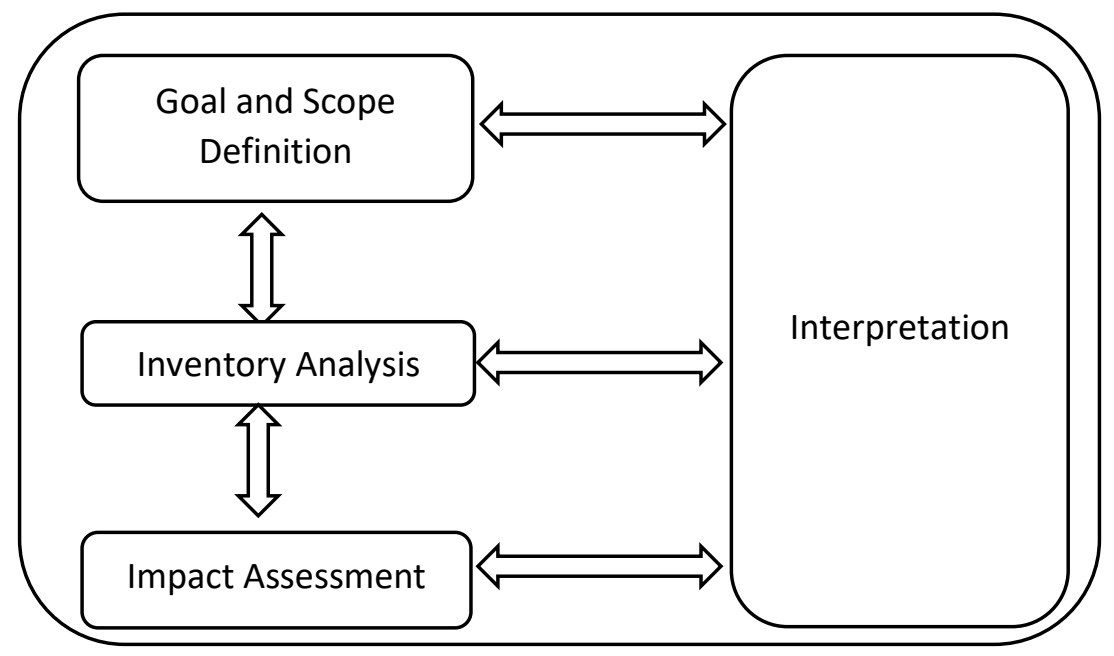

Figure: Phases of an LCA (Source: ISO 1997)

LCA is extremely important for sustainability assessment because it lets us better understand the true impact of any process. By doing a life cycle assessment for any manufacturing process, we will be able to find out which process impacts the most on the environment.

\subsection{Flow Diagram:}

The aim is to quantify and compare the environmental impact caused by different processes associated with the manufacturing processes of a traditionally manufactured turbine blade with its counterpart fabricated by powder-based DED additive manufacturing. To find out which data can be collected from Gabi and which we need to collect through experiment, a detailed unit process of the two manufacturing processes indicating the system boundary of the LCA has been made. The tool we are going to use is Life Cycle Assessment (LCA), which enables the assessment of impacts on the environment and human health, as well as resource use, associated with the full life cycle of products or services, including material extraction, production, use and end of life (International Organization for Standardization, 2006). Gabi software is going to be used to build a model and generate the results.

Due to the time constraint and availability of data in Gabi, the available data for the raw material production is used from Gabi instead of doing separate experiments. Moreover, as for the period of end-of-life disposal, both of the two turbines are recycled back for material recycling; therefore, the phase of usage and end-of-life disposal are excluded from the evaluation scopes. In this regard, the life cycle starts from raw material extraction, materials production, materials transportation, and component manufacturing. Also, some simplifications and assumptions are necessary to make the problem manageable. Figure 2 and 3 shows the brief system boundary of the LCA for additive and traditional manufacturing. 


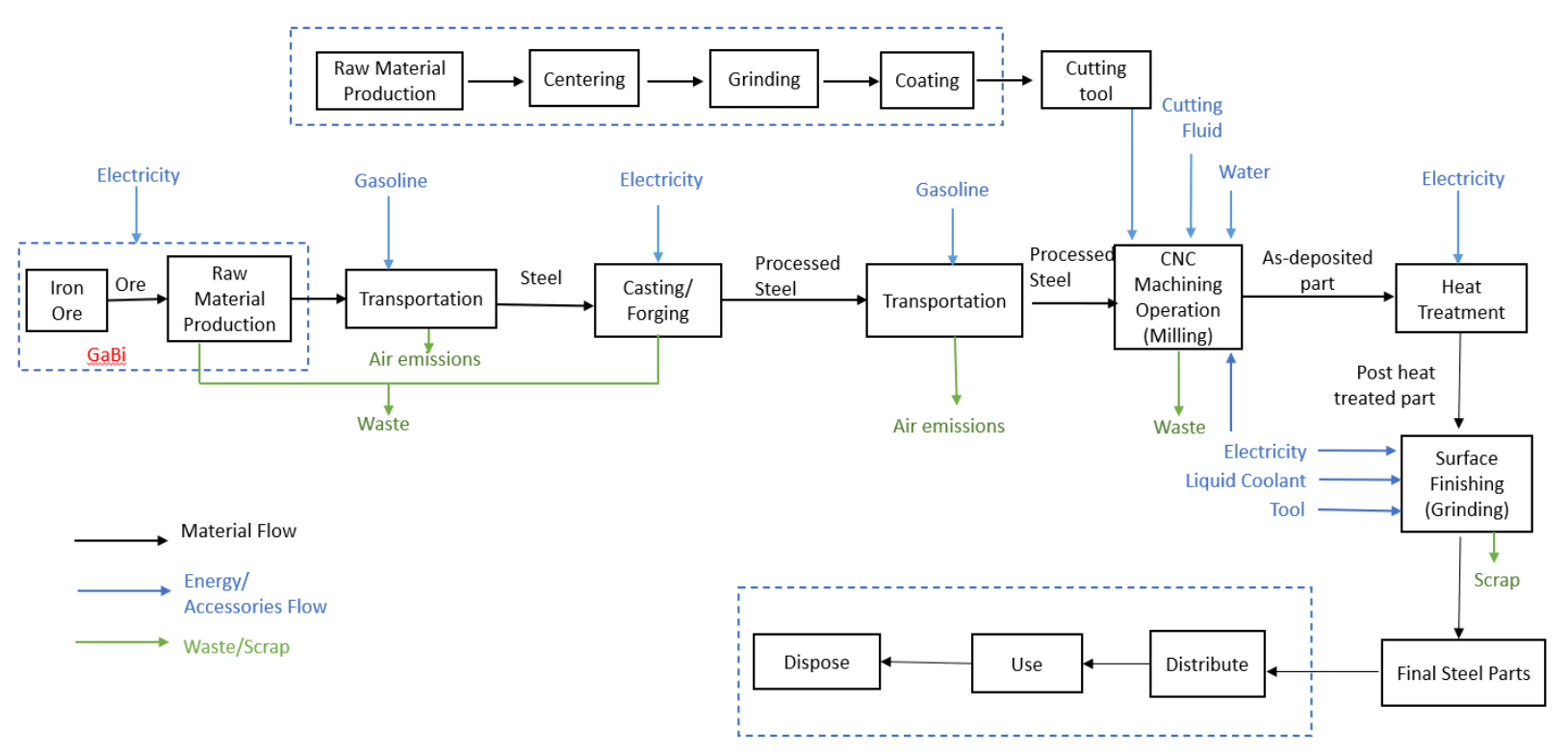

Process flow diagram for CNC Machining

Figure 2: Detailed process flow diagram for CNC Machining

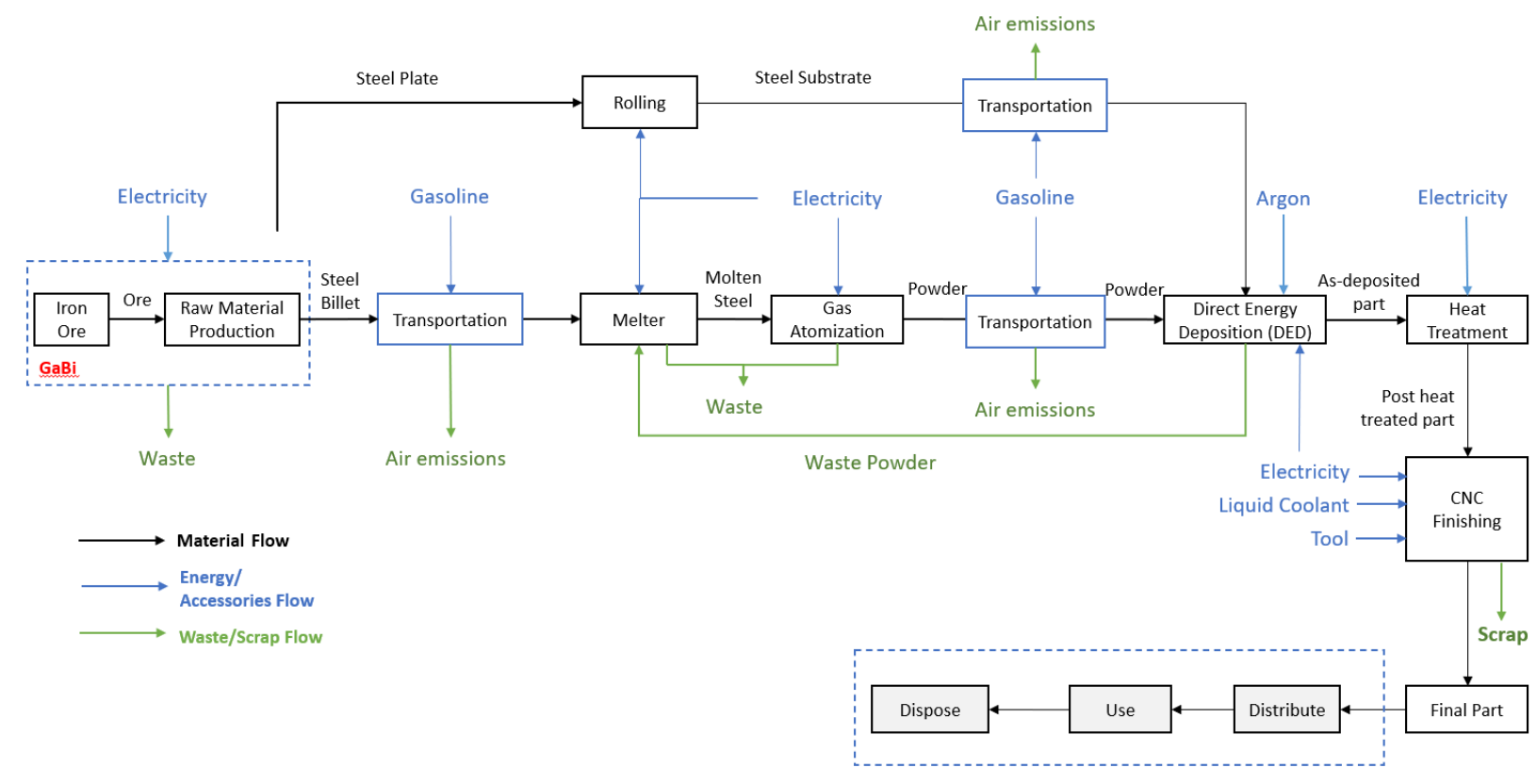

Process flow diagram for Direct Energy Deposition (DED)

Figure 3: Detailed process flow diagram for DED Machining 


\subsection{Quantification of Complexity:}

The materials consumed in the traditional CNC manufacturing process (milling) are steel and coolant. As for the DED process, steel billet, steel plate, and argon are needed during the fabrication process.

While tooling plays a major role in the machining process, the direct environmental impact of tooling is limited. Due to their relatively long life, the environmental cost of tools and tool maintenance is often amortized over numerous products, thereby making the environmental impact relatively insignificant on a per-part basis. However, the effect of tool materials on allowable cutting speeds, and thus on material removal rate, should not be overlooked. The manufacturing process of a cutting tool is generally like below:

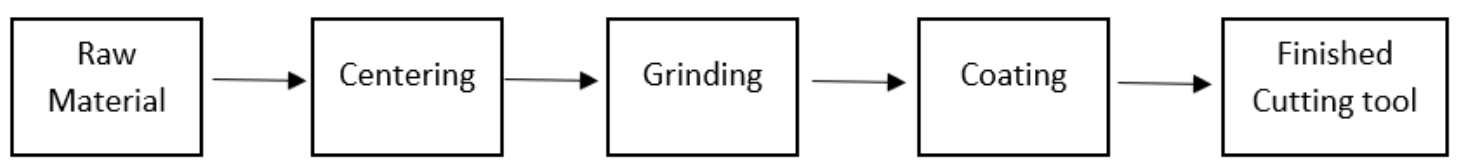

Figure 4: Cutting tool manufacturing process

As the production flow is much complicated for our project to do an experiment on it and take the actual data, we have decided to use the data from the previous study. Today, almost all manufacturing setup uses carabid tools for cutting. Producing carbide tools does require some energy-intensive materials and processes. Jeffrey B. Dahmus (2004) stated that tungsten, with an embodied energy of approximately $400 \mathrm{MJ} / \mathrm{kg}$, comprises most of the mass of carbide cutters. Some of the manufacturing steps, including sintering, which is used to form the carbide tool, and physical vapor deposition (PVD) or chemical vapor deposition (CVD), which is used to coat the carbide, are also quite energy-intensive, with estimates on the order of 1 to $2 \mathrm{MJ}$ per process per cutting insert.

The Shape complexity of a part is usually described in qualitative terms like low, medium, high, and very high. Geometric elements such as internal features (holes, pockets), external features (bosses, ribs), and wall thickness variation result in higher shape complexity. It is a known fact that high shape complexity affects manufacturability, leading to lower quality and productivity, and higher costs of tooling, materials, process, and overheads. The material, process, and overhead costs depend on the part weight, overall production quantity, and part shape complexity. In contrast, the tooling cost is driven more by its machining time, which in turn depends on its shape complexity. This becomes even more important during product development, when several design alternatives need to be prototyped and tested in functional materials, requiring the manufacture of the respective tooling and castings. Thus a reduction in shape complexity of the part can result in improved manufacturability, including significant cost savings.

In this experiment, how the complexity factor impacts environmental impact is studied and an attempt was made to find the sweet spot between DED and CNC in respect of part complexity. 
Geometric features of part design, which influence the design of tooling, determine the complexity of tooling. Here, the considered criteria for shape complexity are Part Volume Ratio, Area Ratio, Number of Cores, and Core Volume Ratio. The criteria equations are set up to return a value between 0 and 1; higher values indicate a greater contribution to complexity. Based on these criteria, the overall shape complexity factor can be estimated by the weighted sum of the individual criteria (Durgesh Joshi, 2010)

\section{$\mathrm{CF}_{\text {estimated }}=\omega_{0}+\omega_{1} \mathrm{CPR}_{\mathrm{P}} \omega_{2} \mathrm{C}_{\mathrm{AR}}+\omega_{3} \mathrm{C}_{\mathrm{NO}}+\omega_{4} \mathrm{COR}$}

Part volume ratio (CPR): This is the ratio of the volume of a part to the volume of a bounding box. The bounding box is given by the maximum length, width, and height of the part geometry. When the volume of the part is close to its bounding box, less material removal is required, resulting in lower machining costs. A Higher difference in these volumes leads to a higher manufacturing cost. This criterion is defined as:

\section{$C_{P R}=1-V_{p} / V_{b}$}

$\mathrm{V}_{\mathrm{p}}$ is the volume of part and $\mathrm{V}_{\mathrm{b}}$ is the volume of its bounding box.

Area ratio ( $\mathbf{C}_{\mathbf{A R}}$ ): This is the ratio of the surface area of an equivalent sphere (with the same volume as that of the part) to the surface area of the part. This ratio is based on the fact that the sphere has a minimum surface area as compared to any other geometry. More features in tooling geometry increase the surface area of tooling. Higher this surface area more will be the cost of machining and hence higher the complexity. This criterion is defined as:

$$
\text { Car }=1-\mathbf{A}_{0} / A_{p}
$$

$A_{o}$ is the surface area of an imaginary sphere with the volume equal to that of the part.

Number of cores ( $\mathbf{C}_{\mathrm{NO}}$ ): Cores are required for hollow portions of the part and regions that hinder pattern withdrawal during molding. Each core requires separate tooling; hence more the number of cored features, the higher will be the tooling cost. The criterion for several cores is defined as follows, considering that the rate of increase in shape complexity increase in the number of cored features:

$\mathrm{C}_{\mathrm{NO}}=1-1 / \sqrt{ }\left(1+\mathrm{N}_{0}\right)$

$\mathrm{N}_{\mathrm{o}}$ is the number of cored features. 
Core volume ratio ( $\mathrm{COR}_{\mathrm{OR}}$ ): Larger cores require larger size tooling and incur higher tooling costs. Hence the ratio of core volume to bounding box volume is included as another measure of complexity.

$\mathrm{COR}=\Sigma \mathrm{V}_{\mathrm{Ci}} / \mathrm{V}_{\mathbf{b}}$

$\mathrm{V}_{\mathrm{Ci}}$ is the volume of $\mathrm{i}_{\text {th }}$ core and $\mathrm{V}_{\mathrm{b}}$ is the volume of the part's bounding box.

\subsection{Hybrid Manufacturing:}

Hybrid manufacturing is the latest addition of technology in the field of additive manufacturing. Hybrid manufacturing is a combination of additive manufacturing (AM) and subtractive manufacturing within the same machine. Both processes on their own have remarkable capabilities, but when combined, it opens up a whole new level of design and manufacturing. Today, most hybrid systems are equipped with a directed energy deposition (DED) head for depositing metal powder or wire and machine tools such as a lathe or mill. These systems allow to make and finish the part in a single setup, reducing error because the AM part does not have to leave one machine to be reset on a second machine.

It depends on the machine system, but nearly any metal available in a wire or powder format could be 3D printed. These include cobalt chrome, copper, aluminum, stainless steel, tool steel and titanium, and many others. One advantage of hybrid metal systems is that they often enable applying dissimilar metals to the same part, for instance, cladding with Inconel for strength or incorporating copper. Polymer systems often use fused filament fabrication and so many different polymer filaments can be used. There are large-scale hybrid systems that use injection molding pellets and may be compatible with composite reinforced polymers. Hybrid polymer systems can also apply multiple materials, for instance, to create an over-molding effect.

Hybrid manufacturing offers several benefits over machining or additive manufacturing alone. Due to additive manufacturing, it is possible to build up and repair damaged parts, or to reduce machining work by starting with a smaller blank and adding material just where it is needed. The Additive Manufacturing technique also allows for the use of multiple materials in a single part, which makes it possible to clad weaker metals for greater strength, add copper to aid heat transfer, or save money on material by applying expensive metals in a very specific spot. When the additive is together with CNC milling in a hybrid system, it is possible to 3D print and finishes a part in a single setup: It reduces error because the printed part does not have to leave the building envelope and be reset on a separate machine. It is also possible to alternate printing and machining to finishing internal features that would be inaccessible in the completed piece.

In this growing and changing technology, using hybrid machines is just another tool in your arsenal. Like any other innovative technology, it takes time to develop and become established. Manufacturers of hybrid machines offer different methodologies for manufacturing.

The first hybrid manufacturing method, and one of the most common, is when additive and subtractive processes are completed in sequence. The part is entirely produced through AM to the 
near net shape and is then machined, where necessary, using subtractive capabilities to finish the part.

The second method alternates between additive and subtractive during the manufacturing process. Whether an existing or new part, AM adds materials, which is then machined, more AM materials are added, and the part goes through another round of machining, and so on until the part is complete. Another example is when a part is machined to finish surfaces while the part is being formed through the additive process.

With hybrid, it is also possible to combine materials during the process and apply different metals to the same part. Nearly any metal is available in both wire or powder format for AM, including aluminum, cobalt chrome, copper, Inconel, stainless steel, tool steel, and titanium, among others. By using different metals in a single part, one can get the best attributes of both parts without compromising the integrity of part.

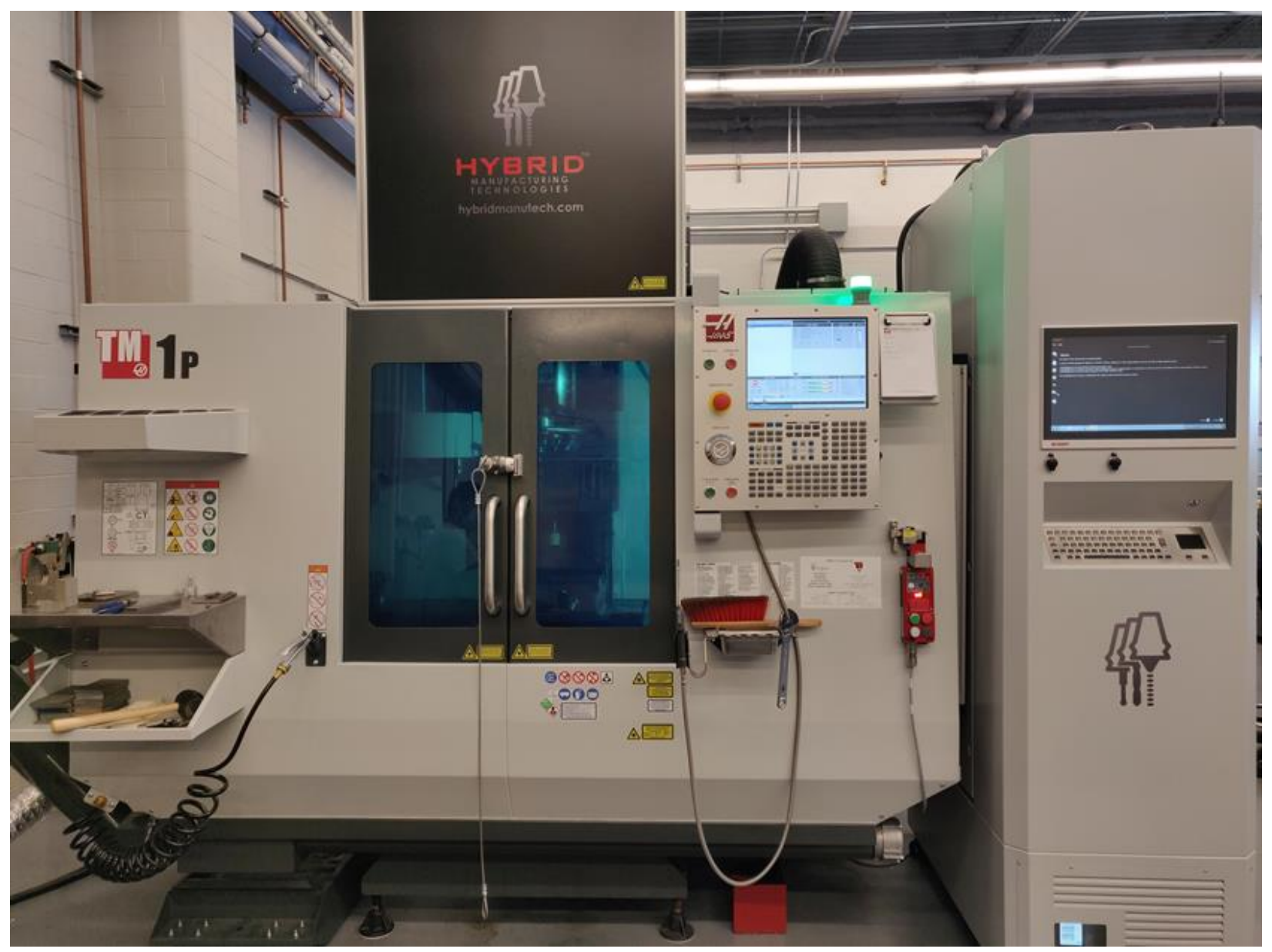

Figure 5: AMBIT laser-based Directed Energy Deposition Hybrid System 


\subsection{Material and Specimen Design:}

For the experiment, a general turbine blade design is selected. For the experiment, the material used is stainless steel powder. Below is the initially selected design which is sketched and simulated by Fusion 360:

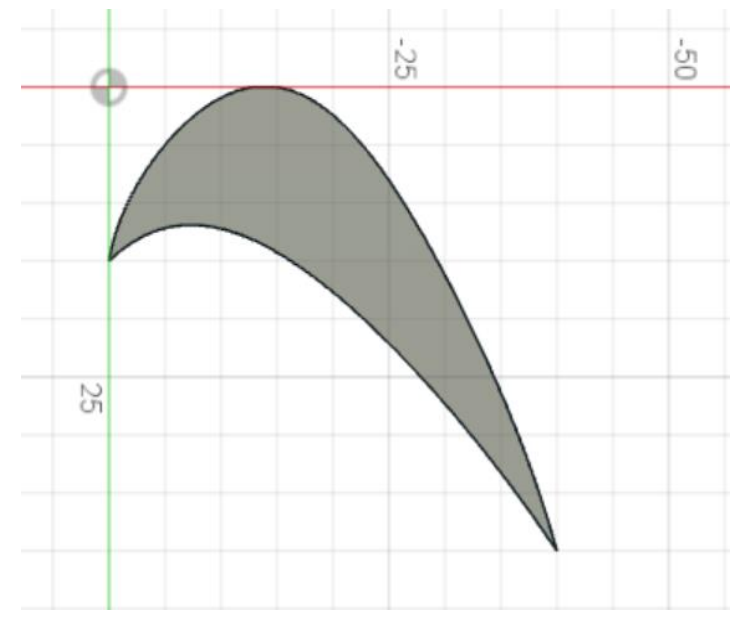

Figure 6: Initial design of turbine blade

After some experiment run it is observed that this design is not achievable with the DED process because the minimum layer thickness of the machine is $1 \mathrm{~mm}$ whereas the corner dimension is below $1 \mathrm{~mm}$ so the material is not distributed evenly and after cooling the edges are damaged and the height of edge is smaller than the body. Below are such experimental outcomes:

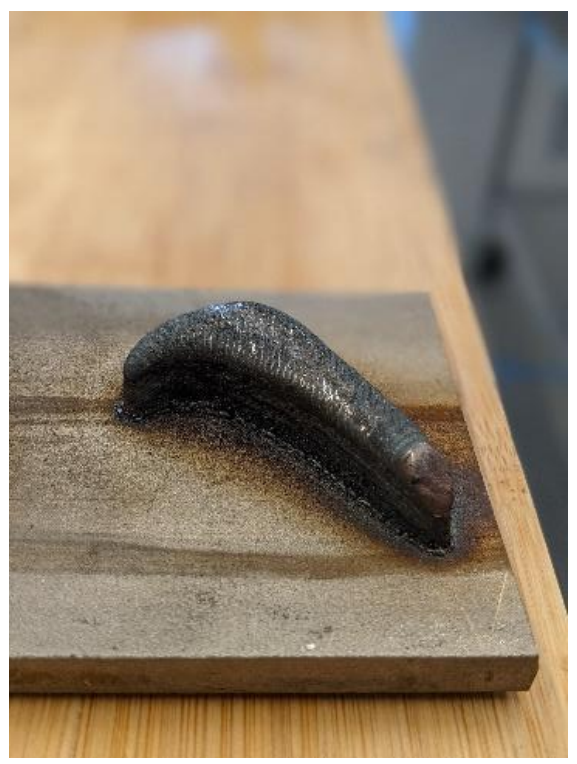

Figure 7: Trial run with initial blade design 


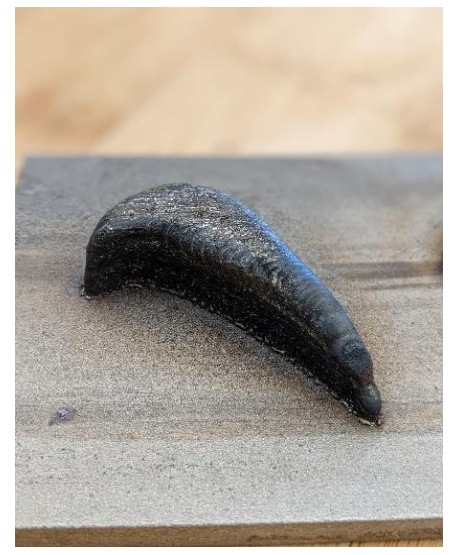

Figure 8: Trial run with initial blade design

So, to avoid damaged edge, the design is slightly modified and some extra margin is added to the design which later would be removed with machining. Below is the final selected design of the turbine blade:

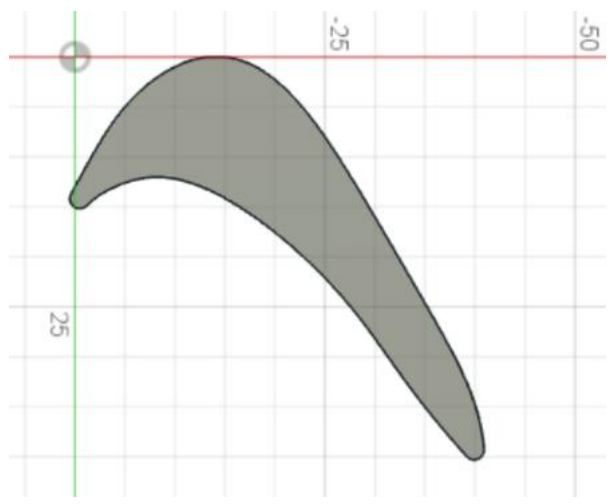

Figure 9: Final blade design

To study how the complexity factor impacts environmental impact and to find the sweet spot between DED and CNC in respect of part complexity, $15 \mathrm{~mm}$ and $25 \mathrm{~mm}$ high is going to be applied. 

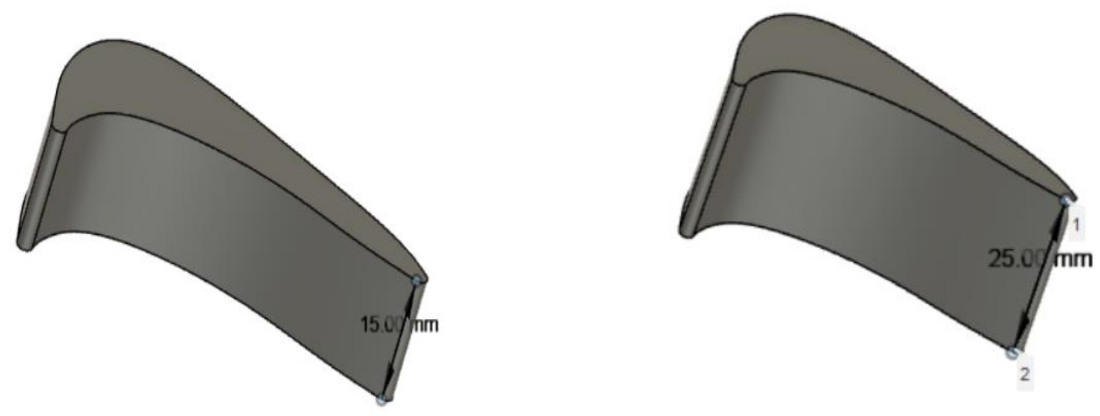

Figure 10: Blade design with different part complexity

\subsection{Data Collection:}

\subsubsection{Data Collection Plan:}

The data which we are going to use for the LCA is collected as below plan:

Table 2: Summary of data collection plan of two manufacturing processes

\begin{tabular}{|c|c|c|c|}
\hline \multicolumn{2}{|c|}{ Process nameLife Cycle Process } & \multirow{2}{*}{\begin{tabular}{|l|} 
Data Source \\
Paper/Internet
\end{tabular}} & Data Type \\
\hline \multirow{5}{*}{ DED } & Gas Atomization & & Calculated \\
\hline & Transportation & Gabi & Modeled \\
\hline & $\begin{array}{l}\text { Direct Energy Deposition } \\
\text { (DED) }\end{array}$ & Lab test & Measured \\
\hline & Heat Treatment & Gabi/Lab Test/Paper & Modeled/Measured/Calculated \\
\hline & CNC Finishing & Lab test & Measured \\
\hline \multirow{6}{*}{$\mathrm{CNC}$} & Casting/ Forging & Paper/Gabi professional & Calculated/ Modeled \\
\hline & Transportation & Gabi & Modeled \\
\hline & \begin{tabular}{|l|} 
CNC \\
Operation (Milling)
\end{tabular} & Lab test & Measured \\
\hline & Tool Manufacturing & Paper & Calculated \\
\hline & Heat Treatment & Gabi/Lab Test/Paper & Modeled/Measured/Calculated \\
\hline & $\begin{array}{|ll|}\text { Surface } & \text { Finishing } \\
\text { (Grinding) } & \end{array}$ & Lab test & Measured \\
\hline
\end{tabular}




\subsubsection{Data Source:}

In this study, the software $\mathrm{GaBi}$ is used for doing Life Cycle Assessment. The GaBi is a software system that offers access to comprehensive and user-friendly functionality to analyze product life cycles or process technologies to deal with Life Cycle Assessment (LCA), Product carbon footprints, Life Cycle costing studies, social aspects, and Design for Environment applications. $\mathrm{GaBi}$ combines the world's leading Life Cycle Assessment (LCA) modeling and reporting software, content databases with intuitive data collection and reporting tools.

$\mathrm{GaBi}$ models every element of a product or system from a life cycle perspective, equipping businesses to make the best-informed decisions on the manufacture and life cycle of a product. It also provides an easily accessible and constantly refreshed content database that details the costs, energy, and environmental impact of sourcing and refining every raw material or processed component of a manufactured item. GaBi helps deliver more sustainable products \& reduce operational costs for the organization \& supply chain by using $\mathrm{GaBi}$ to enhance sustainability decision-making and LCA projects, businesses can build sustainable brands, which consumers increasingly prefer.

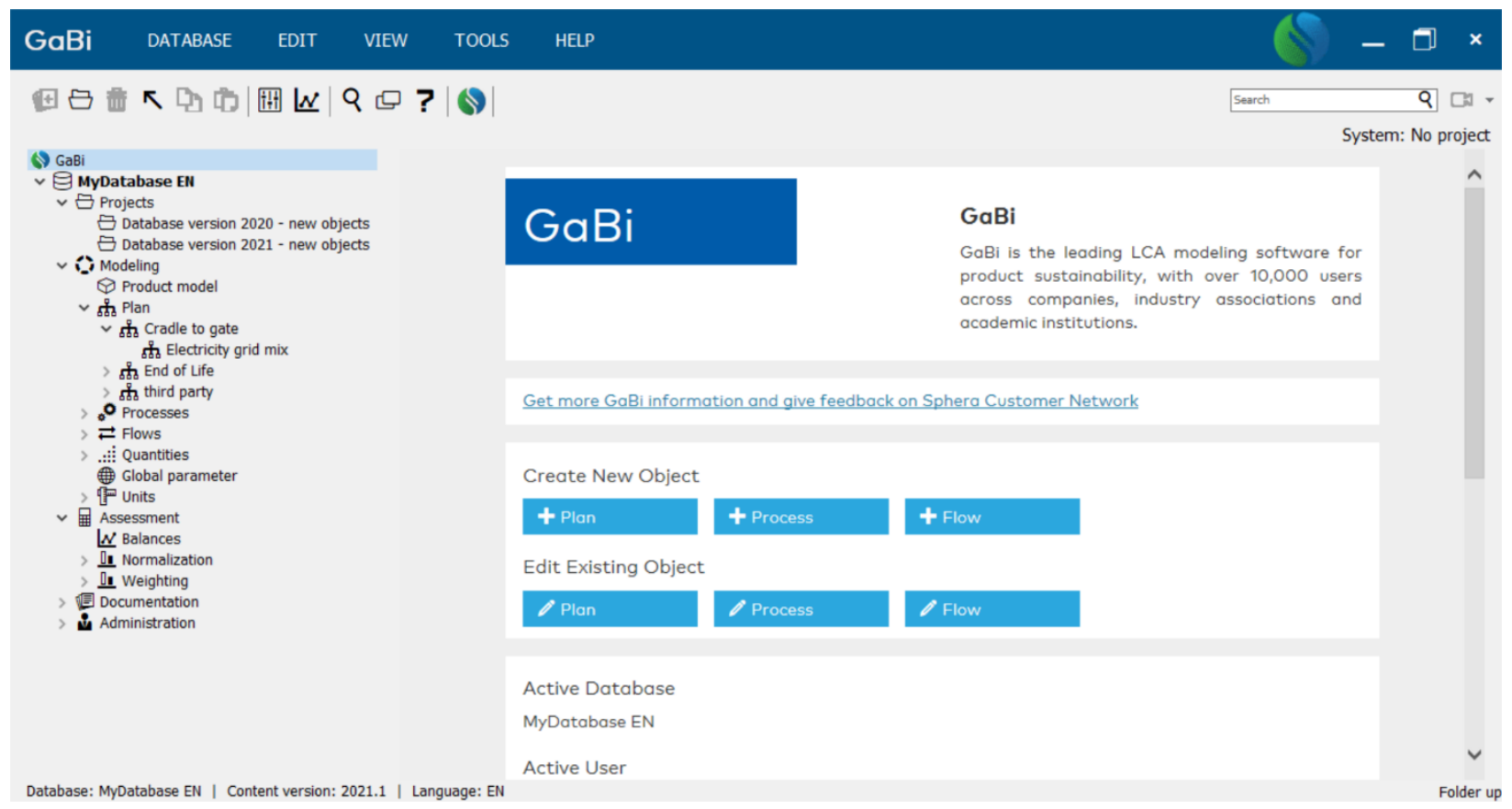

Figure 11: User interface of GaBi professional (2021.1)

The license of this software gives access to the database of previous research and calculation; therefore, it saves a lot of time, energy, and resource for the ongoing study. In this study, GaBi professional version is used to complete the life cycle impact assessment. The version used was 2021.1 which has access to all the recent data. To do the impact assessment, two flow diagram was made which was previously planned and designed. 


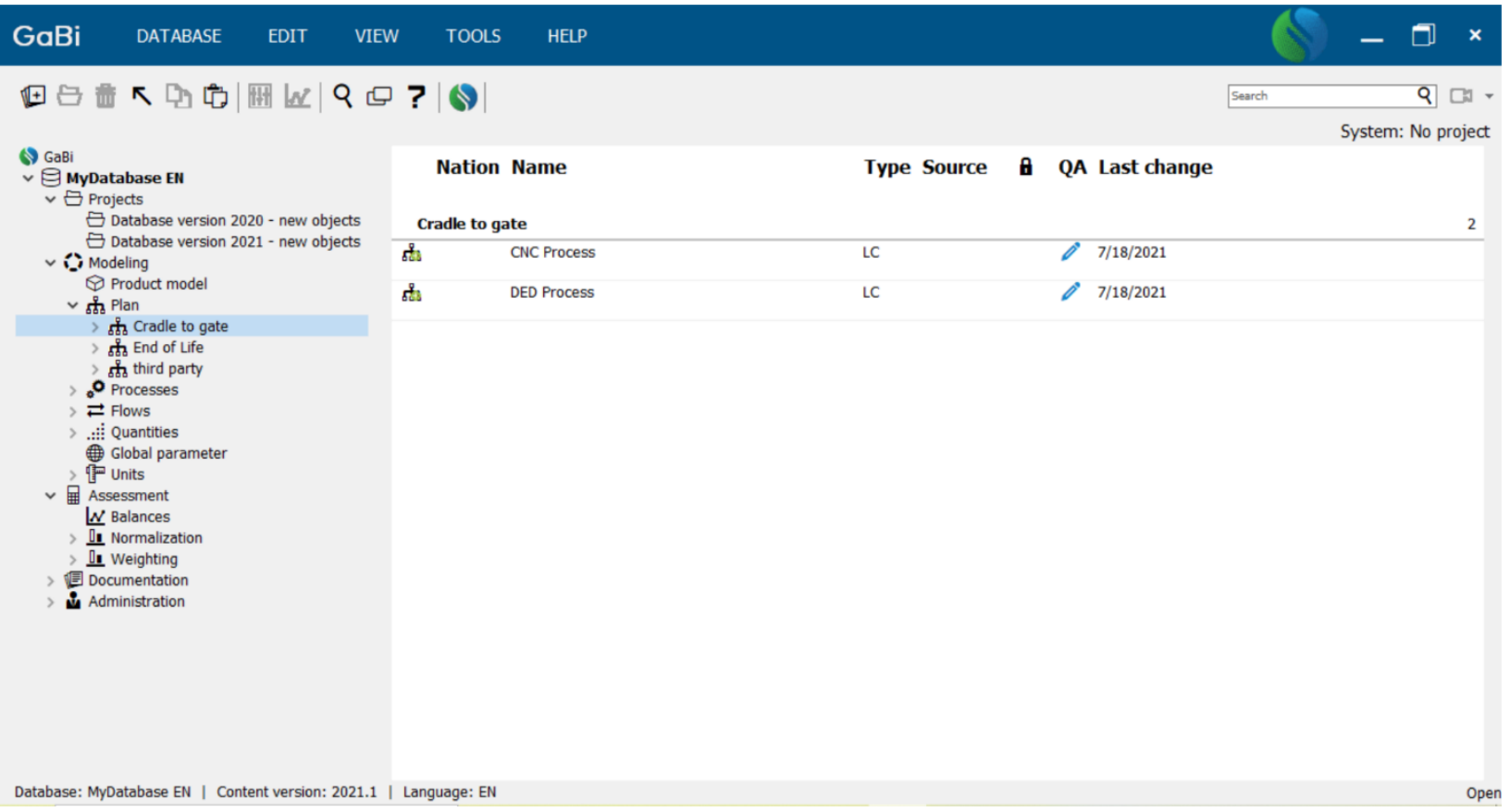

Figure 12: Two processes following the flow diagram

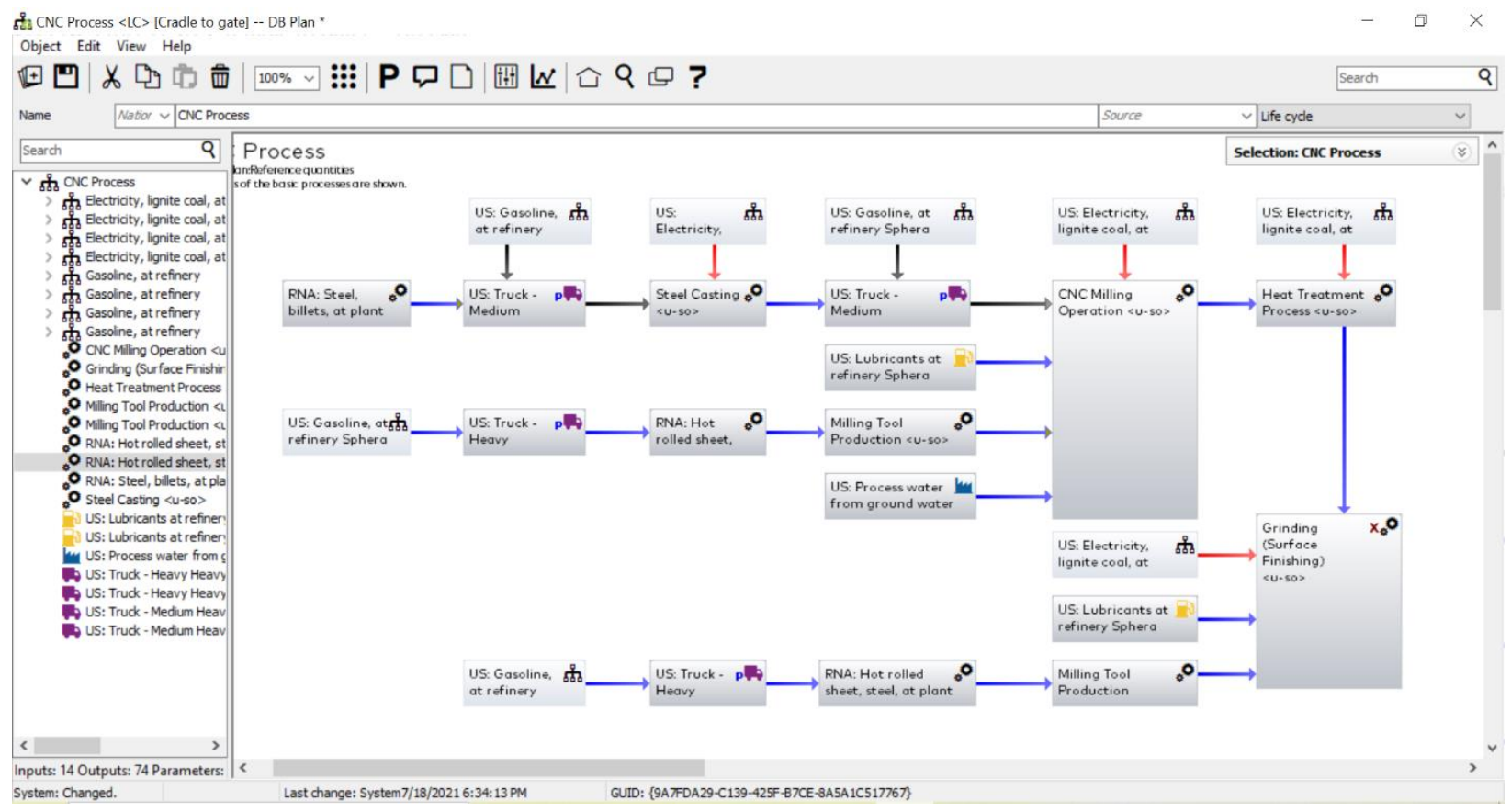

Figure 13: CNC process flow in GaBi professional 


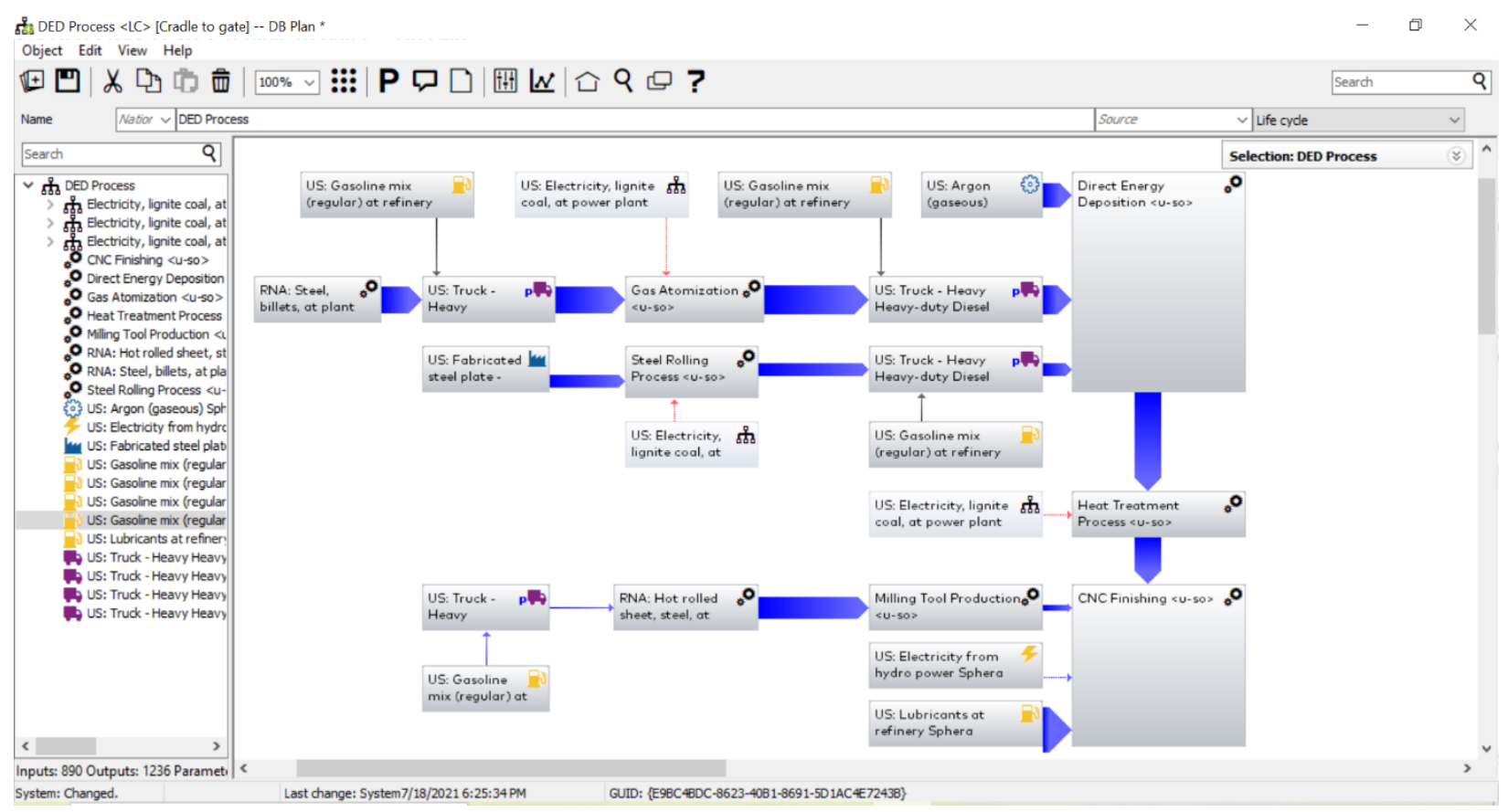

Figure 14: DED process flow in GaBi professional

\subsubsection{Data Collection}

For this study, some experiment was run to get the energy consumption data for different geometrical complexity. In the machine available at the lab G86, there is two power source-one for sunning the leaser and another is for running ambit. To get the power consumption data, consumed electricity was measured using a data logger and a clamp. Those instruments were borrowed from the industrial assessment center.

For the experiment of additive manufacturing, two loggers were used labeled as hobo3 and hobo23. The ampere value was recorded for every one-second interval. At first, the experiment was run for $15 \mathrm{~mm}$ with the DED process where the deposition part took 24 minutes to finish. Gcode was generated with fusion 360 for the design. Below was the used parameter for the experiment:

\section{Table 3: Process parameter for Deposition}

\begin{tabular}{|l|l|}
\hline Laser power & 900 Watt \\
\hline Layer thickness & $1.5 \mathrm{~mm}$ \\
\hline Infill density & $80 \%$ \\
\hline Scanning speed & $10 \mathrm{~mm} / \mathrm{s}$ \\
\hline Powder flow & $5 \mathrm{gm} / \mathrm{min}$ \\
\hline
\end{tabular}


After cooling the specimen, machining was done on the part. For this, surface finishing and contouring-these two milling processes were executed on this. For $15 \mathrm{~mm}$, it took $30 \mathrm{mins}$ to finish the operation while the current data was recorded using Hobo23. Below was the used parameter for the experiment:

Table 4: Process parameter for Machining

\begin{tabular}{|l|l|}
\hline Spindle speed & $1527 \mathrm{rpm}$ \\
\hline Spindle power & $0.6 \mathrm{~kW}$ \\
\hline Chip load & $0.051 \mathrm{mmp}$ \\
\hline Feed rate & $155.20 \mathrm{mmpm}$ \\
\hline Active feed & $155.2 \mathrm{mmpm}$ \\
\hline
\end{tabular}

The same process was done for a $25 \mathrm{~mm}$ blade with the DED process for which 31 mins were required for deposition and 38 mins for the machining. To make the blade with traditional manufacturing, 28 mins was required for $15 \mathrm{~mm}$ blade and $45 \mathrm{mins}$ for $25 \mathrm{~mm}$ blade.

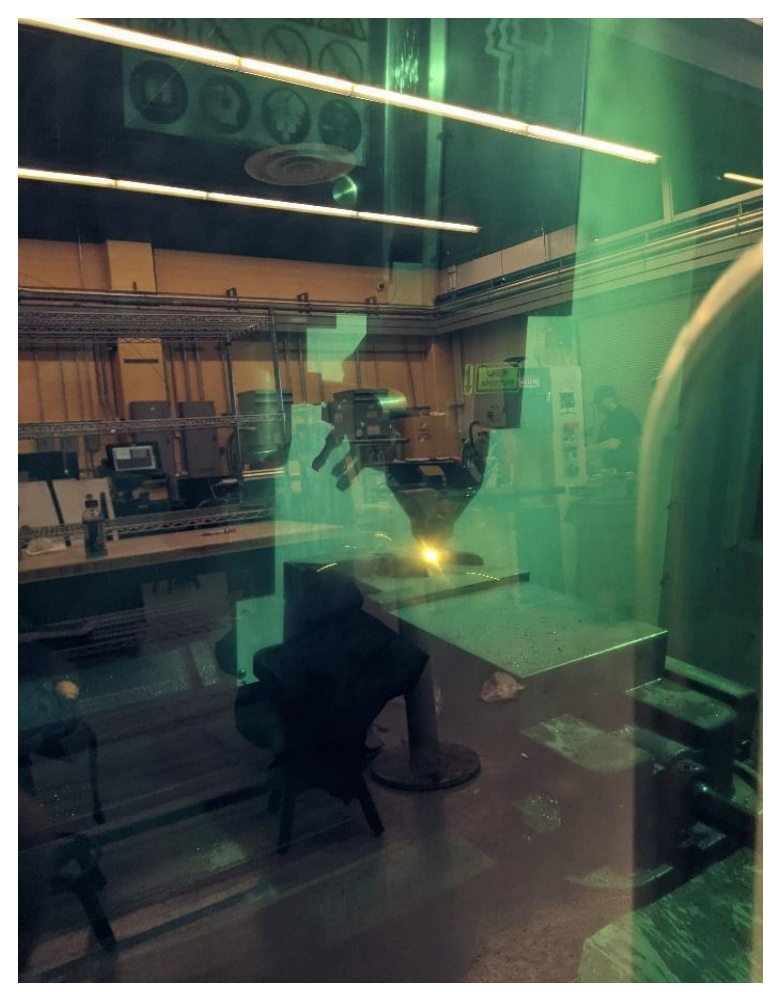

Figure 15: Experiment using AMBIT laser-based Directed Energy Deposition Hybrid System 
Below is one illustration of visualization of how the logger was connected with the power source to get the current data. All necessary safety precaution was followed before working with the wire.

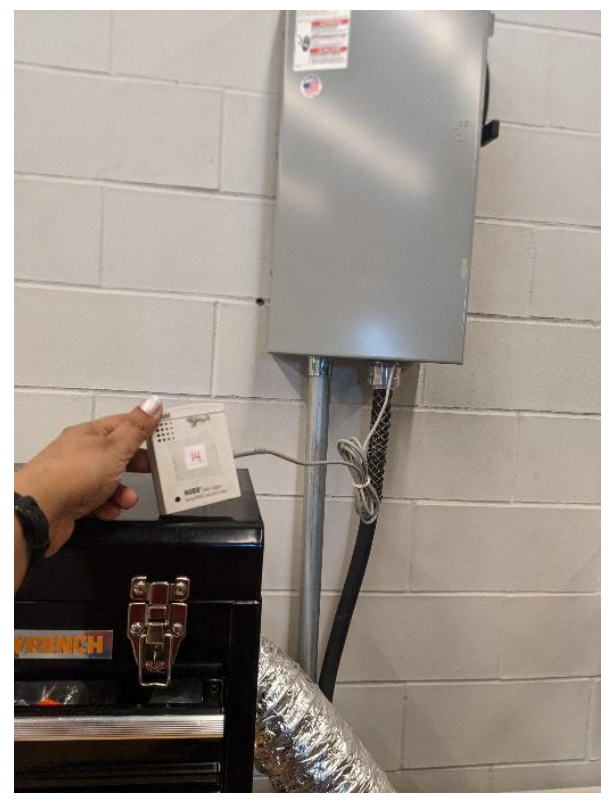

Figure 16: Connection of data logger with the power source

To extract the data from the logger, the latest version of Hobo software was used which gives the data in both excel form and in graph to see how the energy flow has been changed with the pace of time.

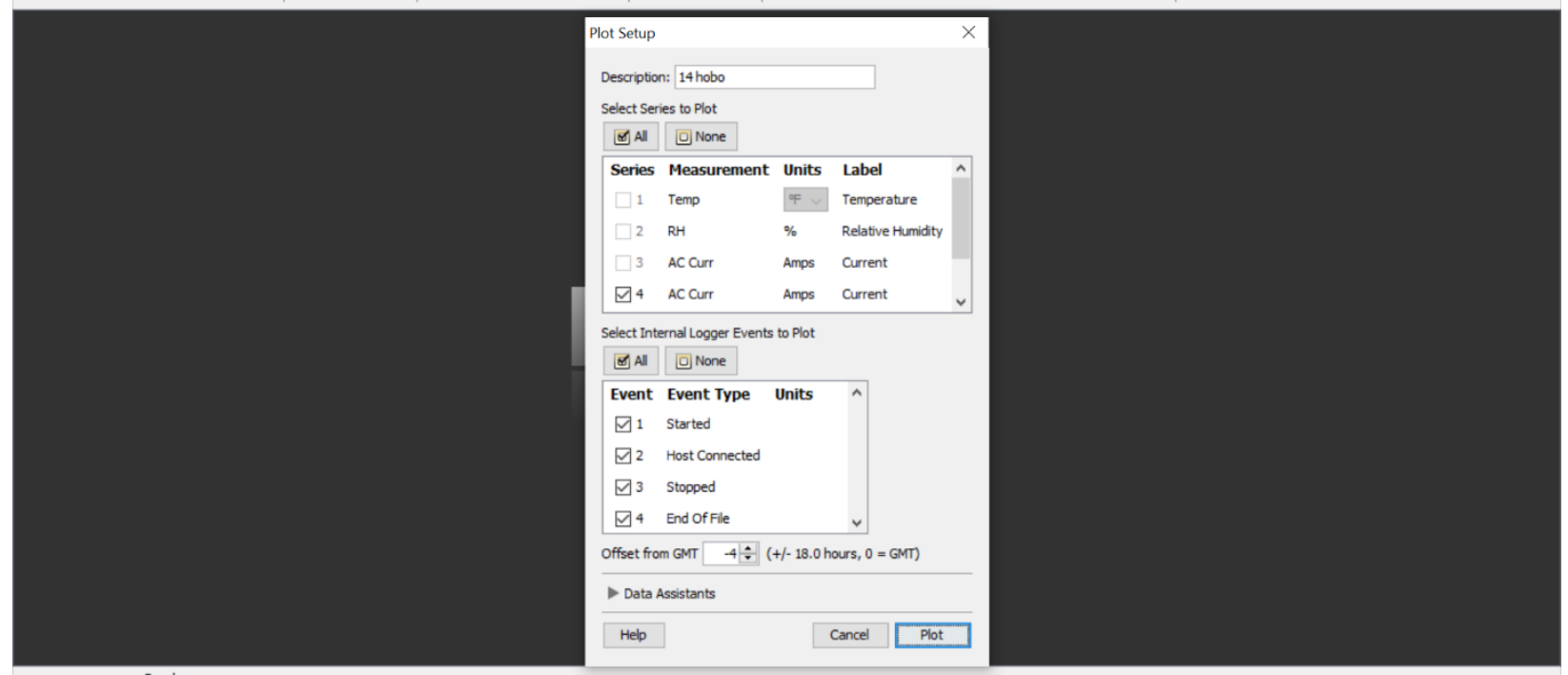




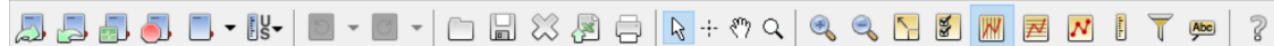

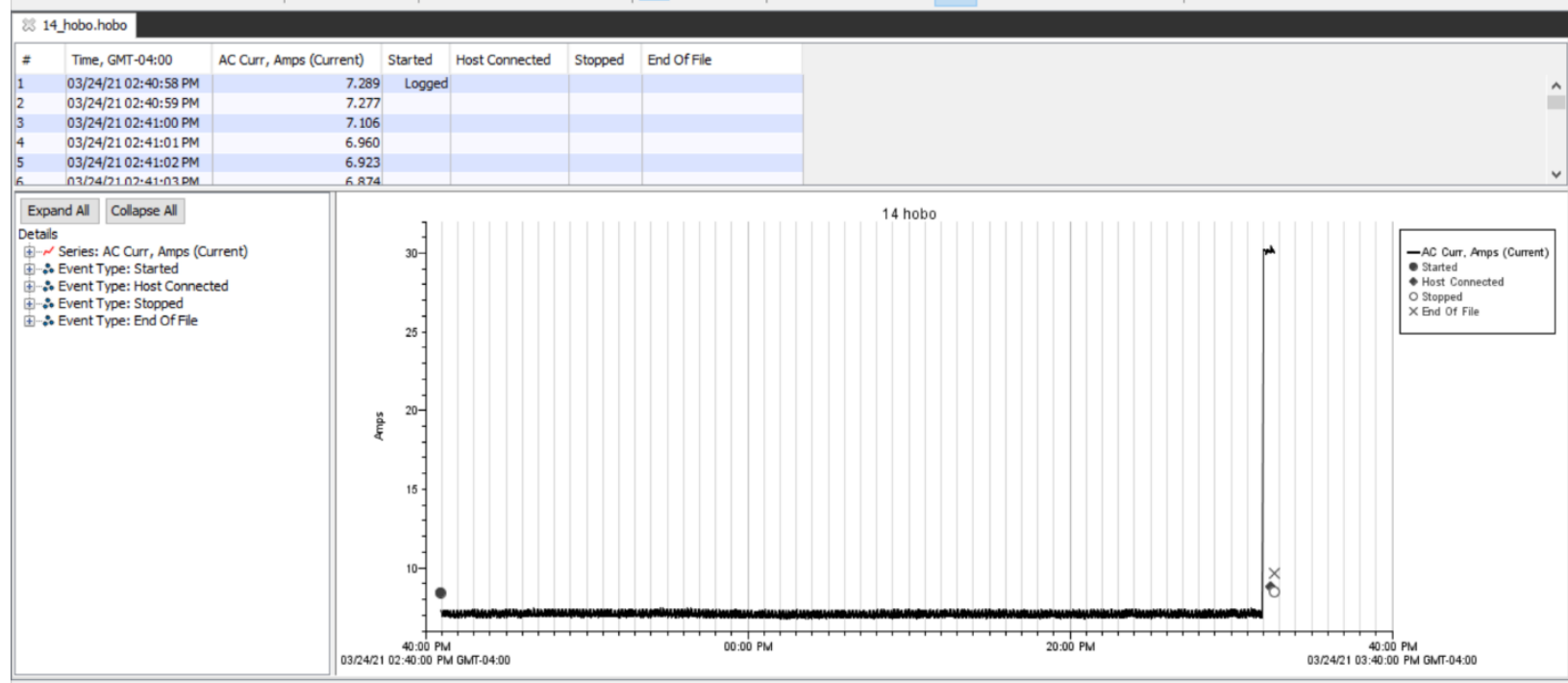

$\square \sqsupseteq 000 \frac{\text { Ready. }}{\text { Dev: No device selected.... }}$

No devices connected

Figure 18: Data visualization of HOBOware

\section{Additive manufacturing current consumption trend}

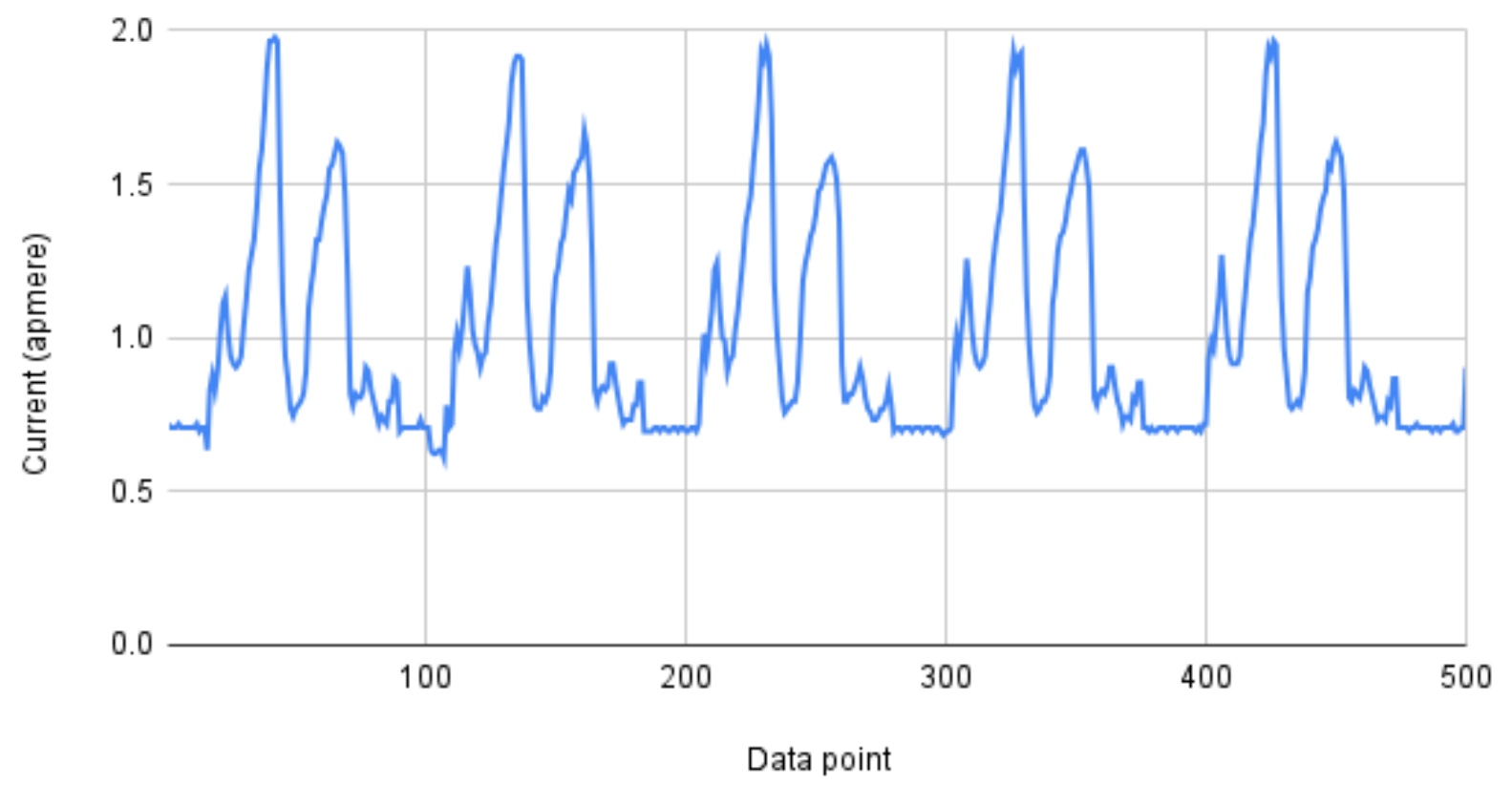

Figure 19: Additive manufacturing current consumption trend 


\section{Subtractive manufacturing current consumption trend}

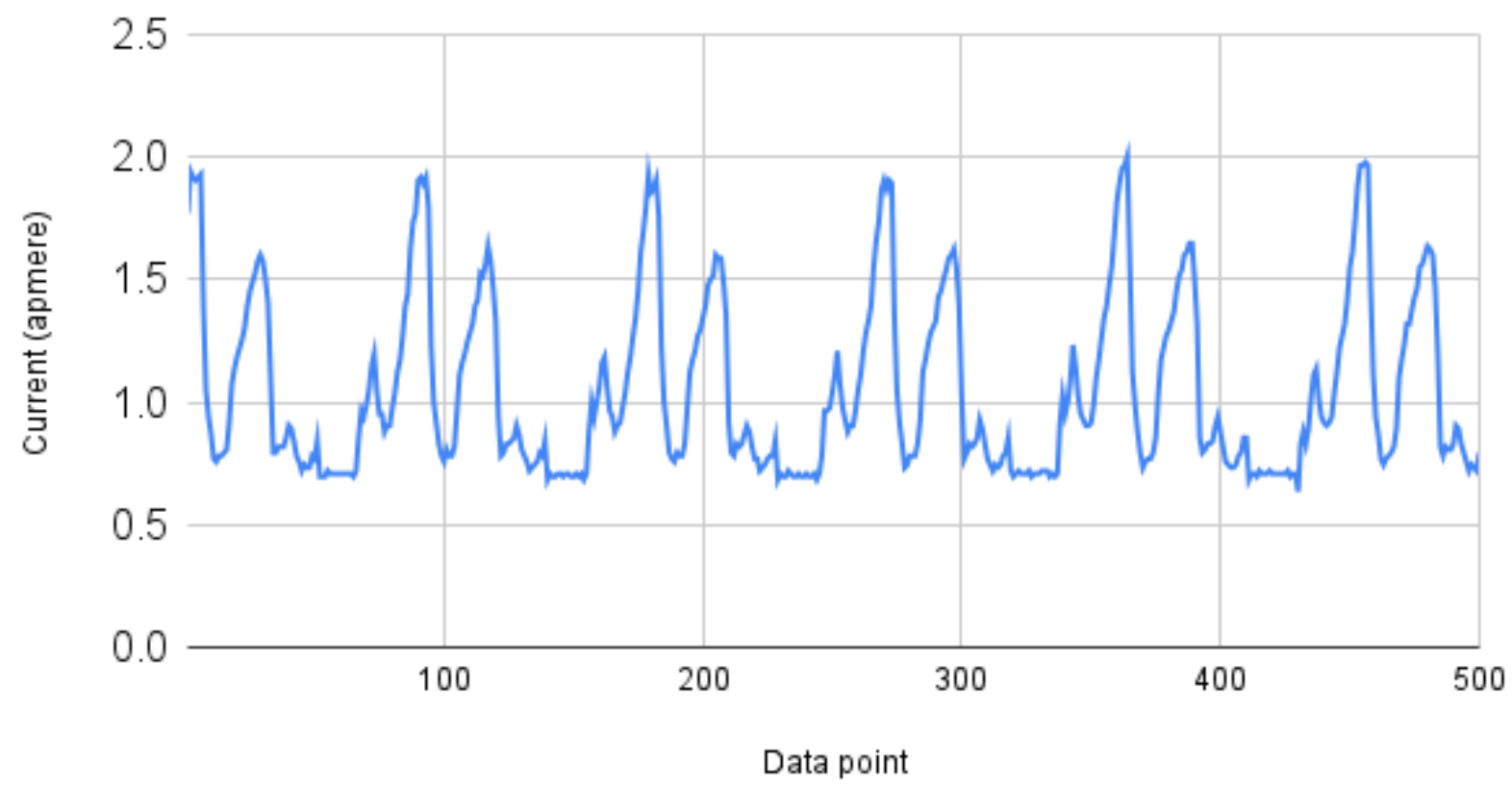

Figure 20: Subtractive manufacturing current consumption trend

Figure 19 and 20 illustrated the trend of electricity consumption during the experiment. The current flow keeps dropping and then going up again according the tool path as the tool path follows the same.

\subsubsection{Evaluation}

To calculate the power consumption value, the below formula was used:

$$
\mathbf{P}=\left(\sqrt{3} \mathbf{3}^{*} V^{*} \mathbf{I} * \mathbf{P f}\right) / \mathbf{1 0 0 0}
$$

Where $\mathrm{P}$ is power, $\mathrm{V}$ is voltage, pf is power factor. For our machine, the voltage was found $240 \mathrm{~V}$, and the power factor was calculated 0.90 by the logger. Later the values were converted into $\mathrm{kWh}$ for easy comparison.

Using this formula for each data point, power data is calculated for each run of every shape complexity. After each process, the weight of the specimen is measured to calculate the waste in each step which is later used as input for LCIA analysis. 
Table 5: Summary of power and material consumption for the DED process

\begin{tabular}{|c|c|c|c|c|}
\hline Complexity & Process & Experimental Image & $\begin{array}{l}\text { Power } \\
\text { consumed }\end{array}$ & $\begin{array}{l}\text { Weight after } \\
\text { process }\end{array}$ \\
\hline \multirow{2}{*}{$15 \mathrm{~mm}$} & Deposited part & & $0.1751 \mathrm{kWh}$ & $0.1382 \mathrm{Kg}$ \\
\hline & CNC finishing & ma & $0.1516 \mathrm{kwH}$ & $0.1275 \mathrm{~kg}$ \\
\hline \multirow[t]{2}{*}{$25 \mathrm{~mm}$} & Deposited part & & $0.3555 \mathrm{kWh}$ & $0.2303 \mathrm{~kg}$ \\
\hline & CNC finishing & & $0.2274 \mathrm{kWh}$ & $0.2125 \mathrm{Kg}$ \\
\hline
\end{tabular}


Table 6: Summary of power and material consumption for CNC process

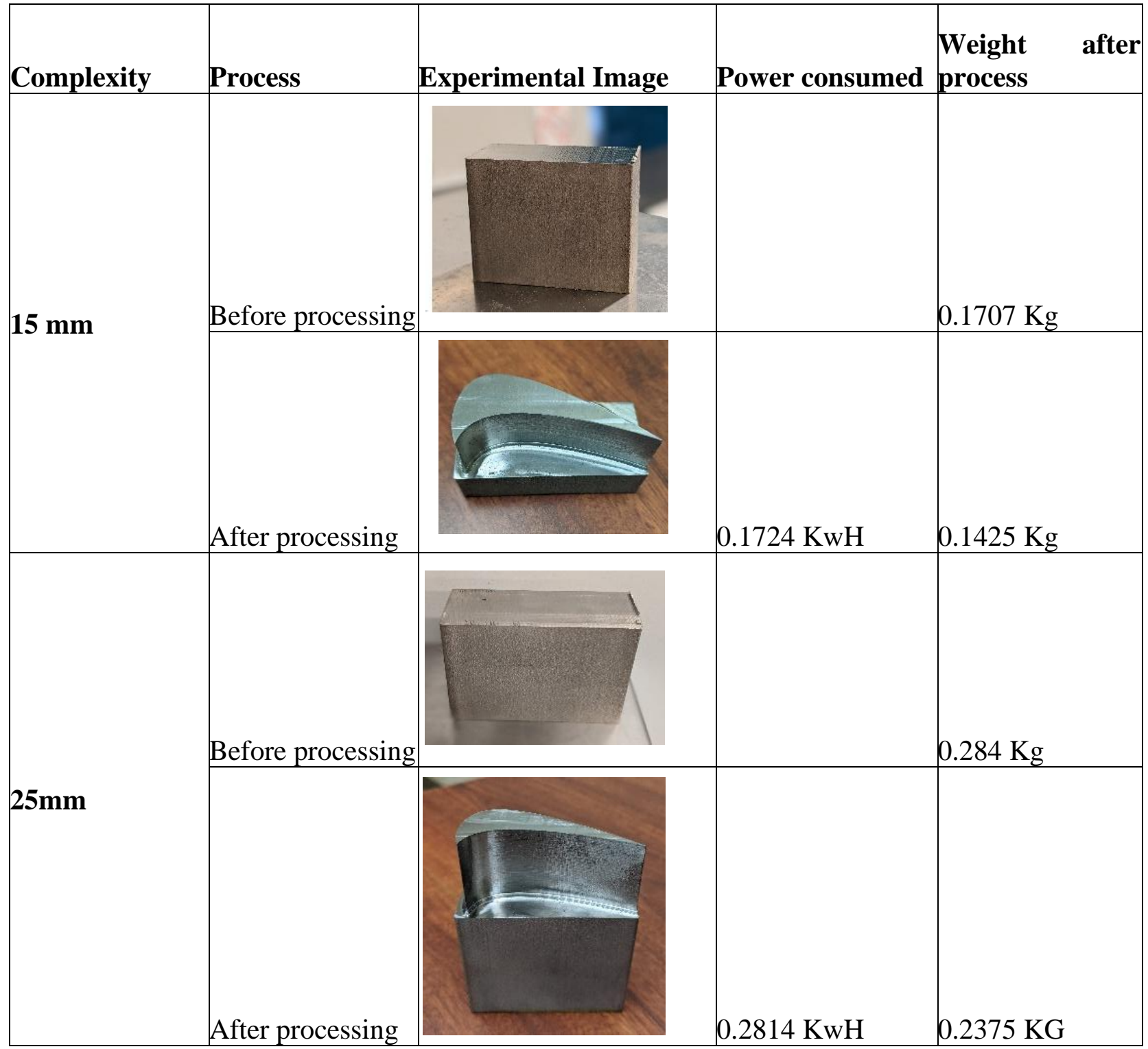

First, the length, width, and height of a part are measured from its CAD model, compute the bounding box volume. Part volume and surface area are obtained using mass property function; equating the volume of the part to the volume of an imaginary sphere, the radius of the sphere is obtained, from which the surface area of the equivalent sphere is computed. 
Table 7: Sample computation of geometry parameters and criteria

\begin{tabular}{|l|l|l|l|l|}
\hline Parameter / Criteria & Unit & $\mathbf{1 5 m m}$ & $\mathbf{2 5 m m}$ & $35 \mathbf{m m}$ \\
\hline L, Length & $\mathrm{mm}$ & 50 & 50 & 50 \\
\hline W, Width & $\mathrm{mm}$ & 20 & 20 & 20 \\
\hline H, Height & $\mathrm{mm}$ & 15 & 25 & 35 \\
\hline Vb: Volume of the bounding box & $\mathrm{mm} 3$ & 15000 & 25000 & 35000 \\
\hline Vp: Volume of part & $\mathrm{mm} 3$ & 7200 & 13750 & 21350 \\
\hline Volume ratio & $\mathrm{mm}$ & 0.48 & 0.55 & 0.61 \\
\hline Criterion part volume ratio: $\mathbf{C P R}_{\mathbf{P R}}$ & & $\mathbf{0 . 5 2}$ & $\mathbf{0 . 4 5}$ & $\mathbf{0 . 3 9}$ \\
\hline Ap: Surface area of the part & $\mathrm{mm} 2$ & 852 & 852 & 852 \\
\hline As: Surface area of imaginary. Sphere & $\mathrm{mm} 2$ & 417.48 & 349.32 & 281.16 \\
\hline Area ratio & $\mathrm{mm}$ & 0.49 & 0.41 & 0.33 \\
\hline Criterion area ratio: CAR & & $\mathbf{0 . 5 1}$ & $\mathbf{0 . 5 9}$ & $\mathbf{0 . 6 7}$ \\
\hline Nc: Number of cores & $\mathrm{mm}$ & 1 & 1 & 1 \\
\hline Criterion number of cores: C C & $\mathbf{m m}$ & $\mathbf{0 . 2 9}$ & $\mathbf{0 . 2 9}$ & $\mathbf{0 . 2 9}$ \\
\hline Total core volume & $\mathrm{mm} 3$ & 300 & 750 & 1400 \\
\hline Criterion core volume ratio: $\mathbf{C C R}$ & & $\mathbf{0 . 0 2}$ & $\mathbf{0 . 0 3}$ & $\mathbf{0 . 0 4}$ \\
\hline
\end{tabular}

The multiple regression analysis is performed using Minitab ${ }^{\circledR}$ statistical analysis software, to compute the weights $\left(\boldsymbol{\omega}_{0}-\boldsymbol{\omega}_{4}\right)$ of equation 5 . The regression equation for estimating shape complexity for new part designs using these weights is presented as equation 7. Analysis of Variance (ANOVA) is presented in table 8:

$$
\mathrm{CF}_{\text {estimated }}=5.2+10.7 \mathrm{C}_{\mathrm{PR}}+19 \mathrm{C}_{\mathrm{AR}}+30.07 \mathrm{C}_{\mathrm{NC}}+32.6 \mathrm{C}_{\mathrm{CR}}
$$

Table 8: Analysis of variance for data sets

\begin{tabular}{|l|l|l|l|l|}
\hline Overall & \multicolumn{5}{l|}{} \\
\hline DF & SS & MS & F & P-value \\
\hline 4 & 3237.61 & 567.02 & 415.08 & 0.001 \\
\hline
\end{tabular}

Table 9: Summary of shape complexity factors

\begin{tabular}{|l|l|l|l|}
\hline & $\mathbf{1 5} \mathbf{m m}$ & $\mathbf{2 5} \mathbf{m m}$ & $\mathbf{3 5 m m}$ \\
\hline $\mathbf{C}_{\mathbf{P R}}$ & 0.52 & 0.45 & 0.39 \\
\hline $\mathbf{C}_{\text {AR }}$ & 0.51 & 0.59 & 0.67 \\
\hline $\mathbf{C}_{\mathbf{N C}}$ & 0.29 & 0.29 & 0.29 \\
\hline $\mathbf{C}_{\mathbf{C R}}$ & 0.02 & 0.03 & 0.04 \\
\hline $\mathbf{C F}_{\text {ESTIMATED }}$ & $\mathbf{2 9 . 8 1 5 5}$ & $\mathbf{3 0 . 9 0 7 1}$ & $\mathbf{3 2 . 1 0 5 7}$ \\
\hline
\end{tabular}




\subsection{Life Cycle Impact Assessment}

An LCA assesses and quantifies the environmental impact of a product or service over its entire life cycle. The main phases of an LCA are goal \& scope setting, inventory analysis, life cycle impact assessment (LCIA), and interpretation. An inventory analysis provides information on all relevant energy and material inputs, and on the emission of toxic and non-toxic pollutants, but that alone does not provide enough information to guide decision-making. To be able to understand the consequences of these inputs and emissions, we need to translate them into environmental impacts. The impact assessment phase provides this translation. The life cycle impact assessment (LCIA) phase is the phase of LCA which helps users to recognize and assess the magnitude and significance of the potential environmental impacts for a product system throughout the life cycle of the product. The motivation of LCIA comes from two observations:

$>$ The final result of the inventory analysis, the inventory table is very long and difficult to handle

$>$ The inventory table contains many items that require expert knowledge to understand their importance.

LCIA methodology does not necessarily attempt to quantify site-specific or actual impacts associated with a product, process, or activity. Rather, the individual impact methods convert LCI results to common units and aggregate the converted results within the same impact categories. By modeling possible impact pathways, LCIA addresses ecological and human health effects, as well as resource depletion, to Hexafluoride duct or processes being studied and its potential environmental impacts.

The LCIA phase consists of four consecutive steps.

- Classification: All substances are sorted into classes according to the effect they have on the environment. A cause-effect pathway shows the causal relationship between the environmental intervention (for instance, the emission of a certain chemical) and its potential effects. LCA professionals can choose impact indicators at different stages in this pathway, for example, the midpoint or endpoint.

- Characterization: All substances are multiplied by a factor that reflects their relative contribution to the environmental impact, quantifying how much impact a product or service has in each impact category. Characterization is the focus of this article.

- Normalization: The quantified impact is compared to a certain reference value, for example, the average environmental impact of a European citizen in one year.

- Weighting: Impact categories are assigned an importance value, and the resulting figures are used to generate a single score. 


\subsubsection{Selection and Definition of Impact Categories:}

The classification method in this analysis is the CML 2000 (baseline) developed by Guinee et al. (2002) with a "midpoint" approach. Five environmental impact categories are assessed in this study, as follows: the global warming potential (GWP), indicated by kilograms ( $\mathrm{kg}$ ) of carbon dioxide equivalents; the acidification potential (AP), expressed as $\mathrm{kg}$ of $\mathrm{SO} 2$ equivalents; the nutrient enrichment potential (EP), indicated by kg of NO3 equivalents; the photochemical ozone formation potential (POCP), indicated by $\mathrm{kg}$ of $\mathrm{C} 2 \mathrm{H} 4$ equivalents; and the ozone depletion potential (ODP), indicated by kg chlorofluorocarbon-11 equivalent. Additionally, a single-issue energy category known as Abiotic Depletion (ADP) is also considered. There are two kinds of ADP calculations, fossil, and element. In this study, fossil ADP is considered which refers to the measure of the use of nonrenewable sources for energy production indicated by MJ in energy.

\subsubsection{Classification:}

Life Cycle Impact Assessment (LCIA) is the step in LCA where the impact of emissions caused by product life cycles is assessed. In this study, five environmental impact categories and a single-issue energy category are assessed:

\section{- Global warming potential (GWP):}

Global warming potential is a reference measure. GWP is expressed on an equivalency basis relative to $\mathrm{CO}_{2}-$ in $\mathrm{kg}$ or tons $\mathrm{CO}_{2}$ equivalent.

Global warming potential is a reference measure. The methodology and science behind the GWP calculation can be considered one of the most accepted LCIA categories. GWP will be expressed on an equivalency basis relative to $\mathrm{CO}_{2}-$ in $\mathrm{kg}$ or tons $\mathrm{CO}_{2}$ equivalent.

Carbon dioxide is the common reference standard for global warming or greenhouse gas effects. All other greenhouse gases are referred to as having a " $\mathrm{CO}_{2}$ equivalence effect" which is simply a multiple of the greenhouse potential (heat-trapping capability) of carbon dioxide. This effect has a time horizon due to the atmospheric reactivity or stability of the various contributing gases over time.

As yet, no consensus has been reached among policy-makers about the most appropriate time horizon for greenhouse gas calculations. The International Panel on Climate Change100-year time horizon figures have been used here as a basis for the equivalence index:

$\mathrm{CO}_{2}$ Equivalent $\mathrm{kg}=\mathrm{CO}_{2} \mathrm{~kg}+\left(\mathrm{CH}_{4} \mathrm{~kg} \times 28\right)+\left(\mathrm{N}_{2} \mathrm{O} \mathrm{kg} \times 265\right)$

A recent IPCC report, "CLIMATE CHANGE 2013 The Physical Science Basis" provided an updated list of GWP equivalence factors, that have not as yet been updated (June 2014) in TRACI, but the Impact Estimator includes updated values for nine of the most common GWP contributors (Methane, Nitrous Oxide (N2O), CFC-11, CFC-12, HCFC-22, HCFC-141b, HCFC-142b, HFC- 
134a, and Sulphur Hexaflouride). When the EPA publishes an updated list of TRACI characterization factors, the Impact Estimator will be updated with all the new factors.

While greenhouse gas emissions are largely a function of energy combustion, some products also emit greenhouse gases during the processing of raw materials. Process emissions often go unaccounted for due to the complexity associated with modeling manufacturing process stages. One example where process $\mathrm{CO}_{2}$ emissions are significant is in the production of cement (calcination of limestone). Because the Impact Estimator uses data developed by a detailed life cycle modeling approach, all relevant process emissions of greenhouse gases are included in the resultant global warming potential index.

\section{- Acidification potential (AP)}

AP is connected to acid deposition of acidifying contaminants on soil, groundwater, surface waters, biological organisms, ecosystems, and substances. SO2, NOx, and $\mathrm{NHx}$ are the main acidifying contaminants. Protection zones are the natural environment, the man-made environment, human health, and natural resources. Acidifying materials reason a widespread collection of influences on soil, groundwater, surface water, organisms, ecosystems, and materials. (Ibrahim Dincer, 2020)

Acidification potential refers to the compounds that are precursors to acid rain. These include sulfur dioxide (SO2), nitrogen oxides ( $\mathrm{NOx}$ ), nitrogen monoxide (NO), nitrogen dioxide (N2O), and other various substances. Acidification potential is usually characterized by $\mathrm{SO} 2$-equivalence. These acid gases are usually released into the atmosphere because of fuel combustion. On the other hand, newly constructed coal-fired power plants have a desulfurization technique to limit the SO2 emissions to the environment. Acidification occurs with substances varying in their acid formation potential.

\section{- Eutrophication Potential (EP):}

Eutrophication Potential (EP) covers the impacts on terrestrial and aquatic environments due to over-fertilization or excess supply of nutrients, particularly focusing on the most important substances nitrogen $(\mathrm{N})$ and phosphorus $(\mathrm{P})$ (Guinée, 2004, p. 82). The enrichment of nutrients leads to increased growth of plants, especially plankton algae, consumption of oxygen by bacteriological degradation of dead biomass, which can change the composition of species. Another impact can be the change of character of a lake, for example, a formerly clean lake with drinking water quality can evolve into the water with an anoxic (free of oxygen) depth layer (Kloepffer and Grahl, 2014, p.261). The impacts of eutrophication on the terrestrial ecosystem are changes in the function and diversity of species.

The Eutrophication Potential is expressed as Phosphate (PO4)-equivalents. The European Space Agency is differentiating within the impact category Eutrophication Potential between "Freshwater Eutrophication Potential" and "Marine Eutrophication Potential". 


\section{- Photochemical ozone formation potential (POCP)}

Photochemical ozone creation potentials (POCPs) typically used in life cycle impact assessment (LCIA) to address the impact category 'photo-oxidant formation' only provide factors for particular volatile organic compounds and do not take into account background concentrations and meteorological conditions. However, the formation of ozone from volatile organic compounds (VOCs), carbon monoxide (CO) and nitrogen oxides (NOx) is highly dependent on the background pollutant concentrations and meteorological conditions. Some LCIA manuals, therefore, recommend working with potentials for high background concentrations of NOx (Derwent 1998), and potentials for low background concentrations of NOx (Andersson-Skold 1992).

\section{- Ozone depletion potential (ODP)}

Ozone depletion potential is measured relative to CFC-11 and it represents the amount of ozone destroyed by the emission of vapor over its entire atmospheric lifetime relative to that caused by the emission of the same mass of CFC-11.

Urban ozone formation potential is expressed relative to ethene. It represents the potential of an organic solvents vapor to form ozone relative to that of ethene ((g O3/g solvent)/(g O3/g ethene)). Several groups of solvents, including alcohols, aldehydes, amines, aliphatic and aromatic hydrocarbons, esters, ethers, and ketones are active in ozone formation. Aldehydes, xylenes, some unsaturated compounds, and some terpenes are the most active among those [48].

\section{- Abiotic Depletion (ADP-Fossil)}

Abiotic depletion potential is a factor that is assessed in LCAs. It refers to the measure of the use of nonrenewable sources for energy production. Abiotic depletion refers to the depletion of nonliving (abiotic) resources such as fossil fuels, minerals, clay, and peat.

In 1995, the original method for assessing the impact category abiotic resource depletion using abiotic depletion potentials (ADPs) was published. The ADP of a resource was defined as the ratio of the annual production and the square of the ultimate (crustal content-based) reserve for the resource divided by the same ratio for a reference resource (antimony (Sb)). In 2002, ADPs were updated based on the most recent USGS annual production data. In addition, the impact category was subdivided into two categories, using two sets of ADPs: the ADP for fossil fuels and the ADP for elements. In this study, ADP fossil is considered. (Lauran et al, 2020)

The characterization factor is the abiotic depletion potential (ADP). This factor is derived for each extraction of elements and fossil fuels and is a relative measure with the depletion of the element 'antimony' as a reference. 


\subsubsection{Characterization}

To quantify how much impact a product or service has in the different impact categories, we use characterization factors (CFs). CFs express how much a single unit of mass of the intervention contributes to an impact category; how much $1 \mathrm{~kg}$ of chemical emission contributes to ecotoxicity, for instance. Let's take the example of ecotoxicity and see how characterization factors can be calculated.

For a proper assessment of the toxic impacts of chemical emissions, researchers need to follow a systematic modeling procedure through the fate, exposure, and effects of the chemical.

- Fate: The environmental fate of a chemical describes the proportion of chemical that is transferred through the environment, and the length of time the chemical stays in the different environmental media.

- Exposure: Various species in an ecosystem can be exposed to chemicals through different uptake routes, such as inhalation of polluted air or ingestion of polluted water. The fate and exposure of chemicals are generally modeled with multimedia fate and exposure models.

- Effects: The effect of a chemical is determined by the sensitivity of a species to that chemical, among other factors, and is often derived from experimental toxicity data.

- Environmental fate: exposure and effects are combined into one quantitative measure, the substance-specific characterization factor.

Different LCIA methods have been developed to characterize the elementary flows crossing the boundary of the studied system into impact categories (third phase of an LCA study). The most accepted and most used characterization methods for LCIA convert the inventoried flows into impact category indicators at the midpoint level (they measure the potential impacts of the studied system unlike the endpoint methods which measure the potential damages to the human health and the ecosystems). Among the available midpoint characterization methods, below are the available ones in $\mathrm{GaBi}$ professional:

- CML 2001-Jan 2016

- Environmental footprint 2.0

- $\mathrm{ReCiPe} 2016$ Midpoint (H)

- TRACI 2.1

The LCIA method chosen to characterize the input and output elementary flows may add uncertainties to the LCA results (Reap, J, 2008). However, choosing a method for calculating the environmental impact of a "product system" is not always obvious. In general, an LCA end-user, which is a non-expert would prefer to have a unique indicator. Nonetheless, using a single indicator is not the purpose of a Life Cycle Assessment. An LCA analyst may have difficulties ranking the impact categories used in the same method to select only the ones representing the greatest impact on the environment. Indeed, how to make a ranking of impact categories that do not measure the same thing (e.g., how to compare the impact of global warming and the impact of acidification). This is the reason why the International Organization for Standardization (ISO) standard 14044 [43] provides an optional process to compare several impact category indicators. 
In this study, CML 2001-Jan 2016 is used which is a midpoint characterization method because of the availability of literature as well as data.

In table 10, the unit for each impact category is mentioned in the second column. For 15 and $25 \mathrm{~mm}$ blades, the experimental data, as well as the data from previous studies, are used as input for the $\mathrm{GaBi}$ model. The outputs are recorded in the table below. From the normalized value, it was visible that most of the environmental impact is coming from the transportation phase of the raw material

Table 10: Characterized value for DED process

\begin{tabular}{|c|c|c|c|c|c|c|c|c|}
\hline \multicolumn{9}{|c|}{ Characterized value } \\
\hline DED & Unit & $15 \mathrm{~mm}$ & $25 \mathrm{~mm}$ & $35 \mathrm{~mm}$ & $45 \mathrm{~mm}$ & $55 \mathrm{~mm}$ & $65 \mathrm{~mm}$ & $75 \mathrm{~mm}$ \\
\hline GWP & $\begin{array}{l}\mathrm{Kg} \mathrm{CO} 2 \\
\text { equivalent }\end{array}$ & 5.44 & 8.7 & 11.96 & 15.22 & 18.48 & 21.74 & 25 \\
\hline $\mathbf{A P}$ & $\begin{array}{l}\mathrm{Lg} \mathrm{SO} 2 \\
\text { equivalent }\end{array}$ & 0.0263 & 0.0421 & 0.0579 & $\begin{array}{l}0.4542 \\
3\end{array}$ & $\begin{array}{l}0.7271 \\
2\end{array}$ & $\begin{array}{l}1.1234 \\
5\end{array}$ & $\begin{array}{l}1.3963 \\
3\end{array}$ \\
\hline EP & $\begin{array}{l}\text { Kg NO3 } \\
\text { equivalent }\end{array}$ & $\begin{array}{l}-1.00 \mathrm{E}- \\
03\end{array}$ & $\begin{array}{l}-1.60 \mathrm{E}- \\
03\end{array}$ & $\begin{array}{l}- \\
0.0022\end{array}$ & $\begin{array}{l}0.4545 \\
5\end{array}$ & $\begin{array}{l}0.7272 \\
7\end{array}$ & $\begin{array}{l}1.1840 \\
2\end{array}$ & $\begin{array}{l}1.4567 \\
5\end{array}$ \\
\hline ODP & $\begin{array}{l}\mathrm{Kg} \\
\text { Chloroflurocarb } \\
\text { on II equivalent }\end{array}$ & $\begin{array}{l}1.78 \mathrm{E}- \\
08\end{array}$ & $\begin{array}{l}2.80 \mathrm{E}- \\
08\end{array}$ & $\begin{array}{l}3.8 \mathrm{E}- \\
08\end{array}$ & $\begin{array}{l}0.4659 \\
7\end{array}$ & $\begin{array}{l}0.7329 \\
8\end{array}$ & $\begin{array}{l}1.1989 \\
5\end{array}$ & $\begin{array}{l}1.4659 \\
7\end{array}$ \\
\hline POCP & $\begin{array}{l}\text { Kg C2H4 } \\
\text { equivalent }\end{array}$ & $\begin{array}{l}2.54 \mathrm{E}- \\
03\end{array}$ & $\begin{array}{l}4.06 \mathrm{E}- \\
03\end{array}$ & $\begin{array}{l}0.0055 \\
8\end{array}$ & 0.4552 & 0.7276 & $\begin{array}{l}1.1772 \\
2\end{array}$ & $\begin{array}{l}1.4496 \\
2\end{array}$ \\
\hline $\begin{array}{l}\text { ADP } \\
\text { (fossil) }\end{array}$ & MJ & $\begin{array}{l}1.11 \mathrm{E}+0 \\
2\end{array}$ & $\begin{array}{l}1.78 \mathrm{E}+0 \\
2\end{array}$ & 245 & $\begin{array}{l}0.4530 \\
6\end{array}$ & $\begin{array}{l}0.7265 \\
3\end{array}$ & $\begin{array}{l}- \\
243.82\end{array}$ & $\begin{array}{l}- \\
243.55\end{array}$ \\
\hline
\end{tabular}

Table 11: Characterized value for CNC process

\begin{tabular}{|c|c|c|c|c|c|c|c|c|}
\hline \multicolumn{9}{|c|}{ Characterized value } \\
\hline $\mathrm{CNC}$ & Unit & $15 \mathrm{~mm}$ & $25 \mathrm{~mm}$ & 35mm & $45 \mathrm{~mm}$ & $55 \mathrm{~mm}$ & $65 \mathrm{~mm}$ & $75 \mathrm{~mm}$ \\
\hline GWP & $\begin{array}{l}\mathrm{Kg} \mathrm{CO} 2 \\
\text { equivalent }\end{array}$ & 6.94 & 12.9 & 18.86 & 24.82 & 30.78 & 36.74 & 42.7 \\
\hline $\mathbf{A P}$ & $\begin{array}{l}\mathrm{Lg} \mathrm{SO} 2 \\
\text { equivalent }\end{array}$ & 0.0501 & 0.0841 & 0.1181 & 0.1521 & 0.1861 & 0.2201 & 0.2541 \\
\hline EP & $\begin{array}{l}\mathrm{Kg} \mathrm{NO} 3 \\
\text { equivalent }\end{array}$ & $\begin{array}{l}-1.01 \mathrm{E}- \\
03\end{array}$ & $\begin{array}{l}-6.94 \mathrm{E}- \\
04\end{array}$ & $\begin{array}{l}- \\
0.0004\end{array}$ & $-6 \mathrm{E}-05$ & $\begin{array}{l}0.0002 \\
5\end{array}$ & $\begin{array}{l}0.0005 \\
7\end{array}$ & $\begin{array}{l}0.0008 \\
9\end{array}$ \\
\hline ODP & $\begin{array}{l}\mathrm{Kg} \\
\text { Chloroflurocarbo } \\
\text { n II equivalent }\end{array}$ & $\begin{array}{l}9.26 \mathrm{E}- \\
09\end{array}$ & $\begin{array}{l}1.27 \mathrm{E}- \\
08\end{array}$ & $\begin{array}{l}1.6 \mathrm{E}- \\
08\end{array}$ & 2E-08 & $\begin{array}{l}2.3 \mathrm{E}- \\
08\end{array}$ & $\begin{array}{l}2.6 \mathrm{E}- \\
08\end{array}$ & $3 \mathrm{E}-08$ \\
\hline $\begin{array}{l}\text { POC } \\
\text { P }\end{array}$ & $\begin{array}{l}\mathrm{Kg} \mathrm{C} 2 \mathrm{H} 4 \\
\text { equivalent }\end{array}$ & $\begin{array}{l}7.52 \mathrm{E}- \\
03\end{array}$ & $\begin{array}{l}1.04 \mathrm{E}- \\
02\end{array}$ & $\begin{array}{l}0.0132 \\
8\end{array}$ & $\begin{array}{l}0.0161 \\
6\end{array}$ & $\begin{array}{l}0.0190 \\
4\end{array}$ & $\begin{array}{l}0.0219 \\
2\end{array}$ & 0.0248 \\
\hline ADP & MJ & $\begin{array}{l}2.79 \mathrm{E}+0 \\
2\end{array}$ & $\begin{array}{l}4.39 \mathrm{E}+0 \\
2\end{array}$ & 599 & 759 & 919 & 1079 & 1239 \\
\hline
\end{tabular}


Here, the green marked columns are the calculated value using the experimental data. The yellow marked data are the approximated ones.

Below are some illustrations of each impact category for different part complexity and process. The graphs illustrate the data for the $15 \mathrm{~mm}$ blade by blue and the interpret $25 \mathrm{~mm}$ blade by red. As this will be a very big calculation, estimated values are not illustrated here.

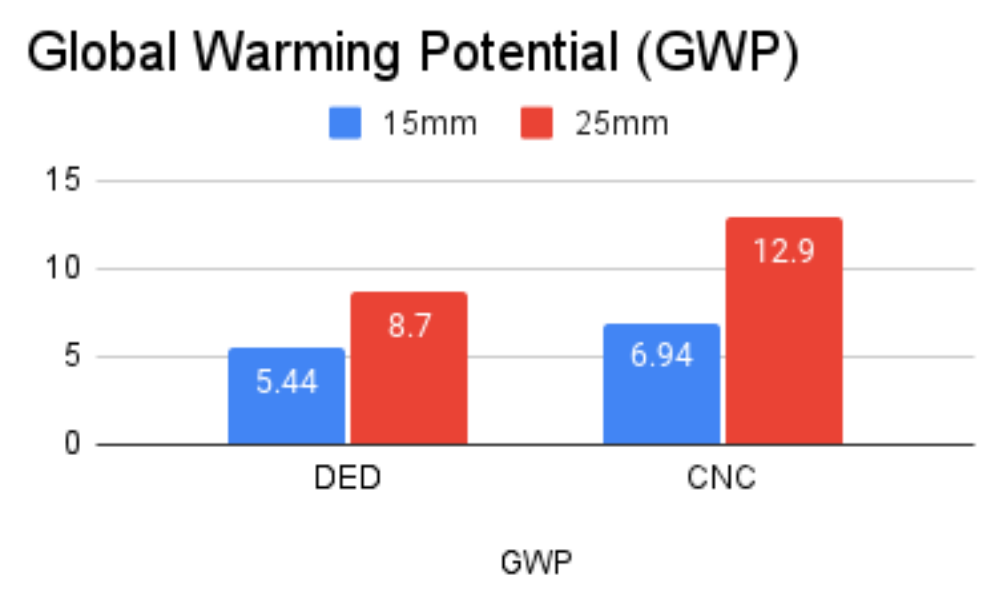

Figure 21: Comparison of GWP for two processes

In this illustration, GWP is shown in $\mathrm{KG}$ of $\mathrm{CO}_{2}$ equivalent scale. With the increment of height, GWP increases for both processes, however, for DED, GWP increases 1.8 where for CNC it increases 1.42 units. This indicates that for GWP, CNC performs better than DED with the increment of height.

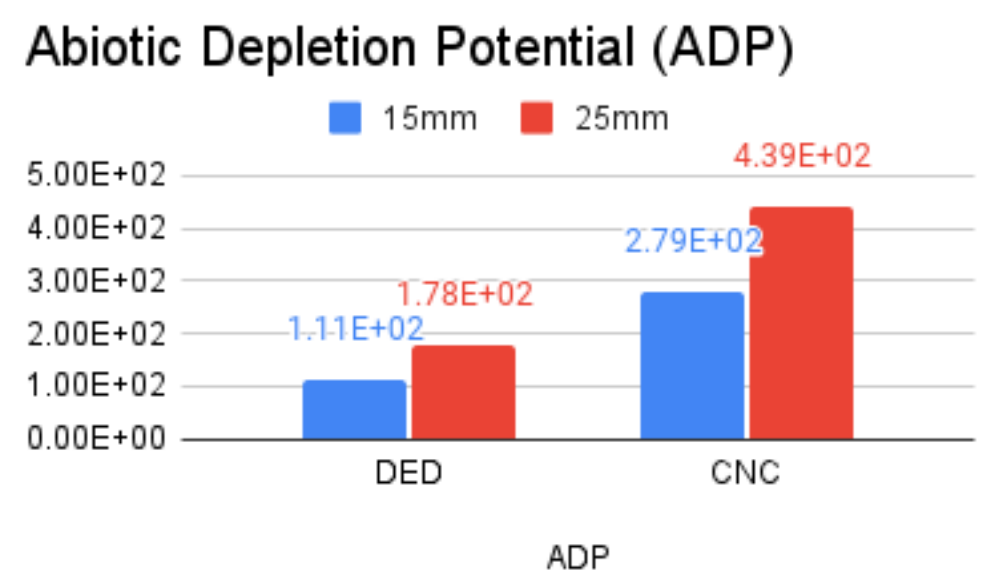

Figure 22: Comparison of ADP for two processes

In this illustration, ADP fossil is shown in MJ equivalent scale. With the increment of height, GWP increases for both processes, however, for DED, ADP increases 37 where for CNC it increases 31 units. This indicates that for ADP, CNC performs better than DED with the increment of height. 


\section{Acidification Potential (AP)}

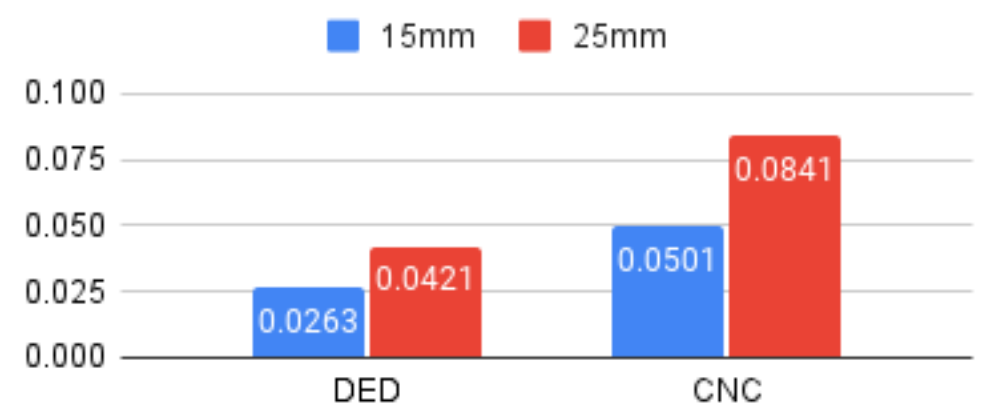

AP

Figure 23: Comparison of AP for two processes

In this illustration, $\mathrm{AP}$ is shown in $\mathrm{KG}$ of $\mathrm{SO}_{2}$ equivalent scale. With the increment of height, $\mathrm{AP}$ increases for both processes, however, for DED, AP increases 0.0066 where for CNC it increases 0.0087 units. This indicates that for ADP, DED performs better than CNC with the increment of height.

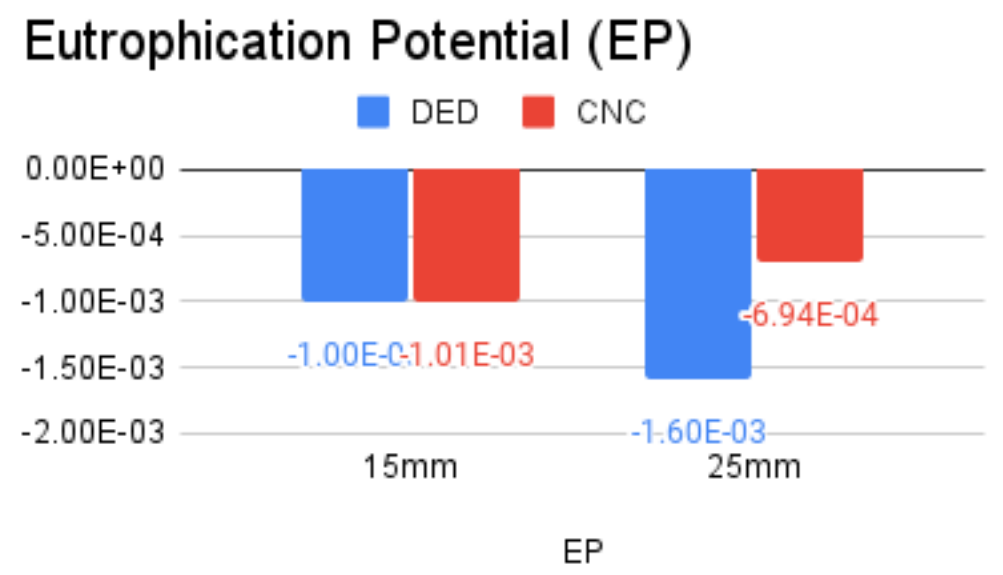

Figure 24: Comparison of EP for two processes

In this illustration, $\mathrm{EP}$ is shown in $\mathrm{KG}$ of $\mathrm{NO}_{3}$ equivalent scale. With the increment of height, $\mathrm{EP}$ increases for both processes. 


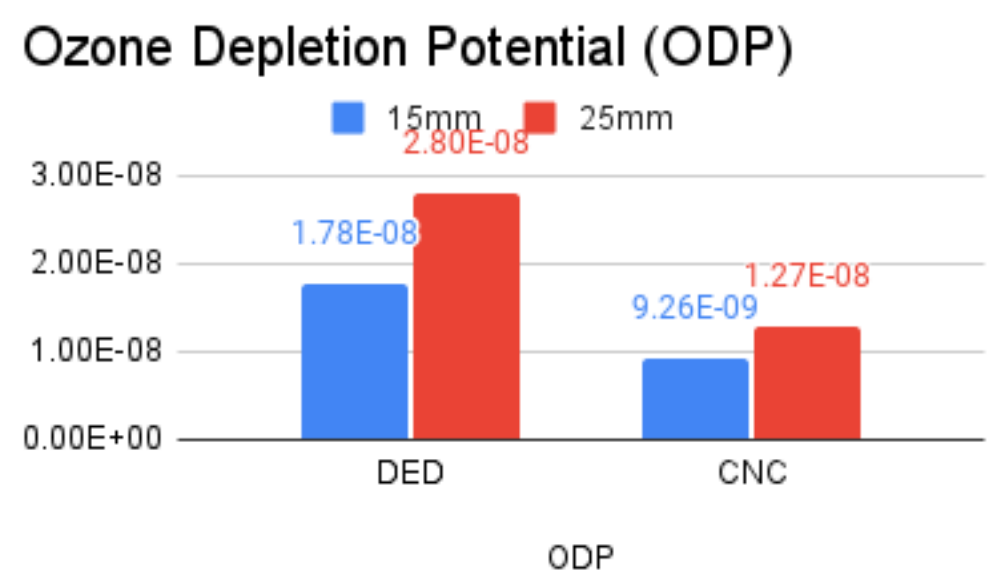

Figure 25: Comparison of ODP for two processes

In this illustration, ODP is shown in KG of Chlorofluorocarbon II equivalent scale. With the increment of height, ODP increases for both processes, however, for DED, AP increases 5.90E09 where for CNC it increases 1.54E-09 units. This indicates that for ADP, DED performs better than $\mathrm{CNC}$ with the increment of part complexity.

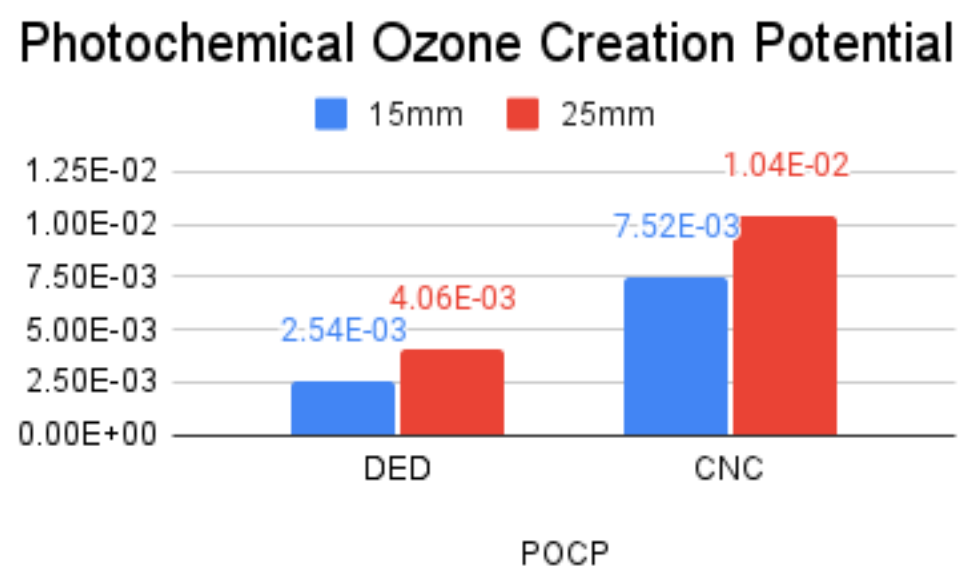

Figure 26: Comparison of POCP for two processes

In this illustration, $\mathrm{POCP}$ is shown in $\mathrm{KG}$ of $\mathrm{C}_{2} \mathrm{H}_{4}$ equivalent scale. With the increment of height, ODP increases for both processes, however, for DED, POCP increases 1.8 where for CNC it increases 1.43 units. This indicates that for POCP, CNC performs better than DED with the increment of part complexity. 
Though the comparison is shown here, it might not be very accurate as the experimental range is not much. From the illustration, it is visible that for some indicators DED performs better whereas, for some others, $\mathrm{CNC}$ is better. As the units are not the same, it is very difficult to declare which process is better altogether. To have one single value in LCA comparison, normalization is introduced.

\subsubsection{Normalization}

The environmental impact scores of life cycle assessments are often presented in units that are difficult to grasp, such as $\mathrm{kg} \mathrm{CO} 2$ equivalents or CTUh. In LCA it is very common to face difficulties to rank the impact categories used in the same method to select only the ones representing the greatest impact on the environment. It is not easy to make a ranking of impact categories that do not measure the same thing e.g., to compare the impact of global warming and the impact of acidification. This is the reason why the International Organization for Standardization (ISO) standard 14044 [43] provides an optional process to compare several impact category indicators which are called Normalization. As defined in the ISO standard 14044, normalization is a process to calculate the magnitude of the results of impact category indicators, relative to some reference information. It is an optional process that can be done to complement an LCIA. The characterized results of each impact category are divided by a selected reference value, which brings all the results on the same scale.

Normalization refers to calculating "the magnitude of the category indicator results relative to some reference information." That refers to normalization as a context provider and indicator of the relative magnitude of an impact indicator. Without normalization, the indicator results are in quite different units, e.g., $\mathrm{Kg} \mathrm{CO}_{2}$ - equivalent for climate change and $\mathrm{MJ}$ primary unit for fossil energy depletion. To put these results into perspective, the normalization expresses them as a share of the total impact size in the region. Arbitrary differences due to a choice of units disappear and it becomes clear to which impact category a product contributes relatively much. The units of the normalization indicator results are equal; nevertheless, such numbers cannot meaningfully be added because the severity of the different impact categories has not yet been accounted for. This can be done in the weighting step.

Normalization can help to interpret LCIA results, providing and communicating information on the relative significance of the impact category indicator results (Kim J, 2013). The normalization results will be more understandable for a non-LCA expert because it is closer to its preoccupations: it makes the understanding of the environmental impact of a product easier when one can compare it to the environmental impact of one person during a full year.

As defined in the ISO standard 14044, normalization is a process to calculate the magnitude of the results of impact category indicators, relative to some reference information. The characterized results of each impact category are divided by a selected reference value, which brings all the results on the same scale.

$$
\mathbf{N}_{\mathrm{i}}=\mathbf{S}_{\mathrm{i}} / \mathbf{R}_{\mathbf{i}}
$$


where $\mathrm{i}$ is the impact category, $\mathrm{N}_{\mathrm{i}}$ is the normalized results, $\mathrm{S}_{\mathrm{i}}$ is the characterized impact of the impact category $\mathrm{i}$ of the system under study, and $\mathrm{R}_{\mathrm{i}}$ is the characterized impact of the impact category $i$ of the reference system.

The reference system can be:

$>$ The total inputs and outputs for a geographical given area over a given reference year.

$>$ The total inputs and outputs for a geographical given area over a given reference year on a per capita basis.

Normalization fulfills several functions, it provides insight into the meaning of the impact indicator results, it helps to check for errors and it prepares for a possible weighting step.

A normalization is an interesting tool, but according to the chosen characterization method and the chosen reference system, LCIA results can vary, and therefore one may not make the right decisions using it.

The equation shows that the normalization is calculated by dividing the impact of a system under study by the impact of the reference system. Uncertainties may exist on both the numerator and the denominator due to some incompleteness. They can come from the category indicator results of the product under study, or the reference system (Heijungs et al, 2007); therefore, the results of the normalization can be too low or too high. Some bias can be found because of the following:

$>$ Uncertainties from the LCIA model and the number of considered substances in the model;

$>$ The reference geographical area of the reference system that can be consistent or not with the area of the studied system; The reference year of the reference system that can be consistent or not with the study;

$>$ The number of considered substances in the reference system.

Table 12 shows the Normalization factors as derived for EDIP97 (Wenzel et al., 1997; Hauschild and Wenzel, 1998). Normalization and weighting factors for the working environment and resources seem to be not available. So, in this study, ADP is compared separately with its characterized value while for the other five indicators, normalization and weighting are done. 
Table 12: Normalization factors (Wenzel et al., 1997)

\begin{tabular}{|l|l|l|l|}
\hline Impact category & Unit & $\begin{array}{l}\text { Normalization } \\
\text { Reference }\end{array}$ & $\begin{array}{l}\text { Reference } \\
\text { Year }\end{array}$ \\
\hline Global Warming Potential (GWP) & $\begin{array}{l}\mathrm{kg} \mathrm{CO} 2- \\
\text { eq/pers/year }\end{array}$ & $8.70 \mathrm{E}+03$ & 1994 \\
\hline Acidification Potential (AP) & $\begin{array}{l}\mathrm{kg} \mathrm{SO}- \\
\text { eq/pers/year }\end{array}$ & 74 & 1994 \\
\hline Eutrophication Potential (EP) -P equivalent & $\mathrm{kg} \mathrm{P-eq/pers/year}$ & -0.4 & 1994 \\
\hline Ozone Depletion Potential (ODP) & $\begin{array}{l}\mathrm{kg} \mathrm{CFC}-11- \\
\text { eq/pers/ar }\end{array}$ & 0.103 & 1994 \\
\hline Photochemical Ozone Creation Potential (POCP) & $\begin{array}{l}\text { kg C2H4- } \\
\text { eq/pers/year }\end{array}$ & 25 & 1994 \\
\hline
\end{tabular}

Using these reference values, normalization is done for five impact categories. At first, it is done for $15 \mathrm{~mm}$ and $25 \mathrm{~mm}$ based on the experimental value. Later data is estimated for 35,45,55,65 and $75 \mathrm{~mm}$ to understand the trend of this data.

Table 13: Normalized value based on experimental data for DED

\begin{tabular}{|c|c|c|c|c|c|}
\hline \multirow{3}{*}{$\begin{array}{l}\text { Environmental } \\
\text { Impact }\end{array}$} & \multicolumn{2}{|c|}{ Characterized Value } & \multirow{3}{*}{$\begin{array}{l}\text { Normalization } \\
\text { Reference }\end{array}$} & \multicolumn{2}{|c|}{ Normalized Value } \\
\hline & \multicolumn{2}{|l|}{ DED } & & \multicolumn{2}{|l|}{ DED } \\
\hline & $15 \mathrm{~mm}$ & $25 \mathrm{~mm}$ & & $15 \mathrm{~mm}$ & $25 \mathrm{~mm}$ \\
\hline GWP & 5.44 & 8.7 & $8.70 \mathrm{E}+03$ & $6.25 \mathrm{E}-04$ & $1.00 \mathrm{E}-03$ \\
\hline AP & 0.0263 & 0.0421 & 74 & \begin{tabular}{|l|}
$3.55 \mathrm{E}-04$ \\
\end{tabular} & \begin{tabular}{|l}
$5.69 \mathrm{E}-04$ \\
\end{tabular} \\
\hline EP & $-1.00 \mathrm{E}-03$ & $-1.60 \mathrm{E}-03$ & -0.4 & $2.50 \mathrm{E}-03$ & $4.00 \mathrm{E}-03$ \\
\hline ODP & $1.78 \mathrm{E}-08$ & $2.80 \mathrm{E}-08$ & 0.103 & $1.73 \mathrm{E}-07$ & $2.72 \mathrm{E}-07$ \\
\hline POCP & $2.54 \mathrm{E}-03$ & $4.06 \mathrm{E}-03$ & 25 & $1.02 \mathrm{E}-04$ & $1.62 \mathrm{E}-04$ \\
\hline
\end{tabular}

Table 14: Normalized value based on experimental data for CNC

\begin{tabular}{|c|c|c|c|c|c|}
\hline \multirow{3}{*}{$\begin{array}{l}\text { Environmental } \\
\text { Impact }\end{array}$} & \multirow{2}{*}{\multicolumn{2}{|c|}{$\begin{array}{l}\text { Characterized Value } \\
\text { CNC }\end{array}$}} & \multirow{3}{*}{$\begin{array}{l}\text { Normalization } \\
\text { Reference }\end{array}$} & \multirow{2}{*}{\multicolumn{2}{|c|}{$\begin{array}{l}\text { Normalized Value } \\
\text { CNC }\end{array}$}} \\
\hline & & & & & \\
\hline & $15 \mathrm{~mm}$ & $25 \mathrm{~mm}$ & & $15 \mathrm{~mm}$ & $25 \mathrm{~mm}$ \\
\hline GWP & 6.94 & 12.9 & $8.70 \mathrm{E}+03$ & $7.98 \mathrm{E}-04$ & $1.48 \mathrm{E}-03$ \\
\hline $\mathbf{A P}$ & 0.0501 & 0.0841 & 74 & $6.77 \mathrm{E}-04$ & $1.14 \mathrm{E}-03$ \\
\hline EP & $-1.01 \mathrm{E}-03$ & $-6.94 \mathrm{E}-04$ & -0.4 & $2.53 \mathrm{E}-03$ & $1.74 \mathrm{E}-03$ \\
\hline$\overline{\text { ODP }}$ & $9.26 \mathrm{E}-09$ & $1.27 \mathrm{E}-08$ & 0.103 & $8.99 \mathrm{E}-08$ & $1.23 \mathrm{E}-07$ \\
\hline POCP & $7.52 \mathrm{E}-03$ & $1.04 \mathrm{E}-02$ & 25 & $3.01 \mathrm{E}-04$ & $4.16 \mathrm{E}-04$ \\
\hline
\end{tabular}


Table 15: Normalized value based on estimated data for DED

\begin{tabular}{|l|l|l|l|l|l|l|l|l|}
\hline & Normalizatio & \multicolumn{2}{l}{ Normalized Value } \\
\cline { 3 - 9 } DED & n Reference & $\mathbf{1 5 m m}$ & $\mathbf{2 5 m m}$ & $\mathbf{3 5 m m}$ & $\mathbf{4 5 m m}$ & $\mathbf{5 5 m m}$ & $\mathbf{6 5 m m}$ & $\mathbf{7 5 m m}$ \\
\hline & & 0.00062 & & 0.00137 & 0.00174 & 0.00212 & 0.00249 & 0.00287 \\
GWP & $8.70 \mathrm{E}+03$ & 5 & 0.001 & 5 & 9 & 4 & 9 & 4 \\
\hline & & 0.00035 & 0.00056 & 0.00078 & 0.00613 & 0.00982 & 0.01518 & 0.01886 \\
AP & 74 & 5 & 9 & 2 & 8 & 6 & 2 & 9 \\
\hline & & & & & - & - & - & - \\
EP & -0.4 & 0.0025 & 0.004 & 0.0055 & 1.13636 & 1.81818 & 2.96005 & 3.64186 \\
\hline & & $1.73 \mathrm{E}-$ & $2.72 \mathrm{E}-$ & $3.71 \mathrm{E}-$ & 4.52396 & 7.11635 & 11.6403 & \\
ODP & 0.103 & 07 & 07 & 07 & 7 & 2 & 2 & 14.2327 \\
\hline & & 0.00010 & 0.00016 & 0.00022 & 0.01820 & 0.02910 & 0.04708 & 0.05798 \\
POCP & 25 & 2 & 2 & 3 & 8 & 4 & 9 & 5 \\
\hline
\end{tabular}

Table 16: Normalized value based on estimated data for CNC

\begin{tabular}{|c|c|c|c|c|c|c|c|c|}
\hline \multirow[b]{2}{*}{ CNC } & \multirow{2}{*}{$\begin{array}{l}\text { Normalizatio } \\
\text { n Reference }\end{array}$} & \multicolumn{7}{|c|}{ Normalized Value } \\
\hline & & $15 \mathrm{~mm}$ & $25 \mathrm{~mm}$ & $35 \mathrm{~mm}$ & $45 \mathrm{~mm}$ & $55 \mathrm{~mm}$ & $65 \mathrm{~mm}$ & $75 \mathrm{~mm}$ \\
\hline GWP & $8.70 E+03$ & 0.000798 & 0.001483 & $\begin{array}{l}0.00216 \\
8\end{array}$ & $\begin{array}{l}0.00285 \\
3\end{array}$ & $\begin{array}{l}0.00353 \\
8\end{array}$ & $\begin{array}{l}0.00422 \\
3\end{array}$ & $\begin{array}{l}0.00490 \\
8\end{array}$ \\
\hline AP & 74 & 0.000677 & 0.001136 & $\begin{array}{l}0.00159 \\
6 \\
\end{array}$ & $\begin{array}{l}0.00205 \\
5\end{array}$ & $\begin{array}{l}0.00251 \\
5\end{array}$ & $\begin{array}{l}0.00297 \\
4 \\
\end{array}$ & $\begin{array}{l}0.00343 \\
4\end{array}$ \\
\hline EP & -0.4 & 0.002525 & 0.001735 & $\begin{array}{l}0.00094 \\
5\end{array}$ & $\begin{array}{l}0.00015 \\
5\end{array}$ & $\begin{array}{l}- \\
0.00064\end{array}$ & 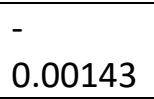 & $\begin{array}{l} \\
0.00222\end{array}$ \\
\hline ODP & 0.103 & 8.99E-08 & $1.23 \mathrm{E}-07$ & $\begin{array}{l}1.57 \mathrm{E}- \\
07\end{array}$ & $1.9 \mathrm{E}-07$ & $\begin{array}{l}2.23 \mathrm{E}- \\
07\end{array}$ & $\begin{array}{l}2.57 \mathrm{E}- \\
07\end{array}$ & 2.9E-07 \\
\hline $\begin{array}{l}\text { POC } \\
\text { P }\end{array}$ & 25 & 0.000301 & 0.000416 & $\begin{array}{l}0.00053 \\
1\end{array}$ & $\begin{array}{l}0.00064 \\
6\end{array}$ & $\begin{array}{l}0.00076 \\
2\end{array}$ & $\begin{array}{l}0.00087 \\
7\end{array}$ & $\begin{array}{l}0.00099 \\
2\end{array}$ \\
\hline
\end{tabular}

\subsubsection{Weighting}

Weighting, like characterization, converts, and aggregates, but while characterization does so for the LCI results, Weighting starts with the characterization or normalization results. Typically, weighting factors are applied, either to the characterization, indicator result, their normalized version. As reflections of value judgments, such as social and political priorities, weighting factors can be obtained in several ways. Weighting typically produces one final number, using:

$$
\mathrm{W}=\Sigma \mathrm{WF}_{\mathrm{c}} \times \mathbf{I}_{\mathrm{c}}
$$

Where Ic symbolizes the impact score or normalized impact score for impact category $\mathrm{c}, \mathrm{WF}_{\mathrm{c}}$ is the weighting factor for this impact category, and $\mathrm{W}$ is the weighted result. The most popular example of such weighted results are the eco-indicator and the ELU (environmental load unit)

Weighting is the optional fourth and final step in Life Cycle Impact Assessment (LCIA), after classification, characterization, and normalization. This final step is perhaps the most debated. 
Weighting entails multiplying the normalized results of each of the impact categories with a weighting factor that expresses the relative importance of the impact category. The weighted results all have the same unit and can be added up to create one single score for the environmental impact of a product or scenario. Simply put, weighting means applying a value judgment to LCA results. It is a controversial step since the weighting factors chosen can influence the results and conclusions of LCA.

Weighting is useful for several reasons. First, it presents LCA results as a single score, which allows you to easily compare the environmental impact of different products or scenarios. This facilitates decision-making since it is immediately clear whether a product's impact is higher than, lower than, or similar to the alternatives. Second, weighting can be very helpful for communication purposes. It is much easier to explain a single score for environmental impact than it is to explain 3 to 18 different scores per product or scenario.

Several impact assessment methods include one or more sets of predefined weighting factors, and each method has its approach for determining them. It is important to be aware of the reasoning behind the weighting factors since they will have an important effect on the results of an LCA. Although each method uses a different approach for determining weighting factors, four basic categories can be determined:

Distance to policy target: Some weighting factors are determined based on policy targets. If the goal for climate change, for example, is to reduce the national $\mathrm{CO} 2$ emissions by $50 \%$ and the goal for acidification is to reduce the national SO2 emissions by $20 \%$, the carbon footprint will get a higher weighting factor. An issue with this approach is that policy targets may not reflect how serious a problem is, since policy may be influenced by costs and other political considerations.

$>$ Distance to scientific target: These weighting factors are based on the same approach as the distance to policy target, but use scientific targets instead. For example, there is a consensus that $350 \mathrm{ppm}$ is the maximum 'safe' level of carbon dioxide in the atmosphere about climate change. These 'safe' levels are used as targets. The further away the current situation is from this target, the higher the weighting level. An issue with this approach is that not every environmental impact category has targets based on scientific data, and that the available scientific targets may not always be up to date.

$>$ Monetization: This approach expresses the relative importance of an impact category in monetary value. This value can be based on the costs associated with preventing or repairing damage; one type of impact may be more expensive to prevent or fix than another. Another way to monetize an impact category is to measure how willing people are to pay to prevent a certain impact. For example, people might be willing to pay more to prevent impacts on human health than to prevent resource depletion. An issue with the monetization approach is that it inherently requires an answer to the question of how much damage is acceptable, and how much the value of human life is. This answer is at best subjective.

$>$ Panel weighting: Perhaps the most straightforward form of determining weighting factors is to simply ask a large group of people for their opinion on what is more important. An 
issue with this approach is that the results can easily be skewed by the personal characteristics of the panelists. Different people have different levels of knowledge about environmental effects and different personal experiences with certain impacts. Beyond that, it is difficult to control the number of explanations panelists are given and the effect of recent media attention on their awareness of certain issues.

Table 17 shows the weighting factors based on the Distance-to-target method as derived for EDIP97 (Wenzel et al., 1997; Hauschild and Wenzel, 1998). Normalization and weighting factors for working environment and resources seem to be not available.

Table 17: Weighting factors based on the Distance-to-target method (Hauschild and Wenzel, 1998)

\begin{tabular}{|l|l|l|l|}
\hline Impact category & $\begin{array}{l}\text { Weighting } \\
\text { Factor }\end{array}$ & $\begin{array}{l}\text { Reference } \\
\text { Year }\end{array}$ & $\begin{array}{l}\text { Reference } \\
\text { Region }\end{array}$ \\
\hline Global Warming Potential (GWP) & 1.1 & 2004 & World \\
\hline Acidification Potential (AP) & 1.3 & 2004 & EU-15 \\
\hline Eutrophication Potential (EP) -P equivalent & 1 & 2004 & EU-15 \\
\hline Ozone Depletion Potential (ODP) & 63 & 2004 & World \\
\hline Photochemical Ozone Creation Potential (POCP) & 1.3 & 2004 & EU-15 \\
\hline
\end{tabular}

Distance-to-target (DTT) methods are weighting methods aimed at assessing the distance of an existing situation from a desired state (the target). Weighting factors in DTT methods could be based on calculation which is performed on normalization factors (NFs) developed for life cycle assessment (LCA). For ODP, the desired state is much distant from the targeted one, therefore, the weighting factor for ODP is highest as per DDT method.

Using these reference values, weighting is done for five impact categories. At first, it is done for $15 \mathrm{~mm}$ and $25 \mathrm{~mm}$ based on the experimental value. Later data is estimated for 35,45,55,65 and $75 \mathrm{~mm}$ to understand the trend of this data. After adding the value for each impact category, we get the final value which is called Environmental Lead Unit for each geometric complexity. 
Table 18: Weighted value based on experimental data for DED

\begin{tabular}{|c|c|c|c|c|c|}
\hline \multirow{3}{*}{ Environmental Impact } & \multirow{2}{*}{\multicolumn{2}{|c|}{\begin{tabular}{|l|} 
Normalized Value \\
DED
\end{tabular}}} & \multirow{3}{*}{ Weighting Factor } & \multicolumn{2}{|c|}{ Weighted Value } \\
\hline & & & & \multicolumn{2}{|l|}{ DED } \\
\hline & $15 \mathrm{~mm}$ & & & $15 \mathrm{~mm}$ & $25 \mathrm{~mm}$ \\
\hline GWP & 0.00063 & 0.001 & 1.1 & $6.88 \mathrm{E}-04$ & $1.10 \mathrm{E}-03$ \\
\hline$\overline{\mathbf{A P}}$ & 0.00036 & 0.00057 & 1.3 & $4.62 \mathrm{E}-04$ & $7.40 \mathrm{E}-04$ \\
\hline EP & 0.0025 & 0.004 & 1 & $2.50 \mathrm{E}-03$ & $4.00 \mathrm{E}-03$ \\
\hline ODP & $1.73 \mathrm{E}-07$ & $2.72 \mathrm{E}-07$ & 63 & $1.09 \mathrm{E}-05$ & $1.71 \mathrm{E}-05$ \\
\hline POCP & 0.0001 & 0.00016 & 1.3 & $1.32 \mathrm{E}-04$ & $2.11 \mathrm{E}-04$ \\
\hline \multicolumn{4}{|l|}{ Environmental Load Unit } & $\begin{array}{l}\text { 3.79E- } \\
03\end{array}$ & $\begin{array}{l}6.07 \mathrm{E}- \\
03\end{array}$ \\
\hline
\end{tabular}

Table 19: Weighted value based on experimental data for DED

\begin{tabular}{|c|c|c|c|c|c|}
\hline \multirow{3}{*}{ Environmental Impact } & \multirow{2}{*}{\multicolumn{2}{|c|}{\begin{tabular}{|l|} 
Normalized Value \\
CNC
\end{tabular}}} & \multirow{3}{*}{ Weighting Factor } & \multicolumn{2}{|c|}{ Weighted Value } \\
\hline & & & & \multicolumn{2}{|c|}{ CNC } \\
\hline & $15 \mathrm{~mm}$ & $25 \mathrm{~mm}$ & & $15 \mathrm{~mm}$ & $25 \mathrm{~mm}$ \\
\hline GWP & 0.0008 & \begin{tabular}{|l|}
0.00148 \\
\end{tabular} & 1.1 & 8.77E-04 & $1.63 \mathrm{E}-03$ \\
\hline $\mathbf{A P}$ & 0.00068 & 0.00114 & 1.3 & 8.80E-04 & $1.48 \mathrm{E}-03$ \\
\hline EP & 0.00253 & 0.00174 & 1 & $2.53 \mathrm{E}-03$ & $1.74 \mathrm{E}-03$ \\
\hline ODP & $8.99 \mathrm{E}-08$ & $1.23 \mathrm{E}-07$ & 63 & $5.66 \mathrm{E}-06$ & 7.77E-06 \\
\hline POCP & 0.0003 & \begin{tabular}{|l|}
0.00042 \\
\end{tabular} & 1.3 & 3.91E-04 & 5.41E-04 \\
\hline \multicolumn{4}{|l|}{ Environmental Load Unit } & $\begin{array}{l}4.68 E- \\
03\end{array}$ & 5.39E-03 \\
\hline
\end{tabular}

Table 20: Weighted value based on estimated data for DED

\begin{tabular}{|c|c|c|c|c|c|c|c|c|}
\hline \multirow{2}{*}{$\begin{array}{l}\text { Environment } \\
\text { al Impact }\end{array}$} & \multirow{2}{*}{$\begin{array}{l}\text { Weightin } \\
\text { g Factor }\end{array}$} & \multicolumn{7}{|c|}{ Weighted Value of DED process } \\
\hline & & $\begin{array}{l}15 \mathrm{~m} \\
\mathrm{~m}\end{array}$ & \begin{tabular}{|l|}
$25 m$ \\
$\mathbf{m}$ \\
\end{tabular} & $\begin{array}{l}35 m \\
\text { m }\end{array}$ & $45 \mathrm{~mm}$ & $55 \mathrm{~mm}$ & $65 \mathrm{~mm}$ & $75 \mathrm{~mm}$ \\
\hline GWP & 1.1 & $\begin{array}{l}6.88 \mathrm{E} \\
-04\end{array}$ & $\begin{array}{l}1.10 \mathrm{E} \\
-03\end{array}$ & $\begin{array}{l}1.51 \mathrm{E} \\
-03\end{array}$ & $\begin{array}{l}1.92 \mathrm{E}- \\
03\end{array}$ & $\begin{array}{l}2.34 \mathrm{E}- \\
03\end{array}$ & \begin{tabular}{|l}
$2.75 \mathrm{E}-$ \\
03
\end{tabular} & $\begin{array}{l}3.16 \mathrm{E}- \\
03\end{array}$ \\
\hline AP & 1.3 & $\begin{array}{l}4.62 \mathrm{E} \\
-04\end{array}$ & \begin{tabular}{|l|}
$7.40 \mathrm{E}$ \\
-04
\end{tabular} & $\begin{array}{l}1.02 \mathrm{E} \\
-03\end{array}$ & $\begin{array}{l}7.98 \mathrm{E}- \\
03\end{array}$ & $\begin{array}{l}1.28 \mathrm{E}- \\
02\end{array}$ & $\begin{array}{l}1.97 \mathrm{E}- \\
02\end{array}$ & $\begin{array}{l}2.45 \mathrm{E}- \\
02\end{array}$ \\
\hline EP & 1 & $\begin{array}{l}2.50 \mathrm{E} \\
-03\end{array}$ & $\begin{array}{l}4.00 \mathrm{E} \\
-03\end{array}$ & $\begin{array}{l}5.50 \mathrm{E} \\
-03\end{array}$ & $\begin{array}{l}- \\
1.14 \mathrm{E}+0 \\
0\end{array}$ & $\begin{array}{l}- \\
1.82 \mathrm{E}+0 \\
0\end{array}$ & $\begin{array}{l}- \\
2.96 \mathrm{E}+0 \\
0\end{array}$ & \begin{tabular}{|l}
- \\
$3.64 \mathrm{E}+0$ \\
0
\end{tabular} \\
\hline ODP & 63 & $\begin{array}{l}1.09 \mathrm{E} \\
-05 \\
\end{array}$ & $\begin{array}{l}1.71 \mathrm{E} \\
-05 \\
\end{array}$ & $\begin{array}{l}2.34 \mathrm{E} \\
-05\end{array}$ & $\begin{array}{l}2.85 \mathrm{E}+0 \\
2\end{array}$ & \begin{tabular}{|l|}
$4.48 \mathrm{E}+0$ \\
2 \\
\end{tabular} & $\begin{array}{l}7.33 \mathrm{E}+0 \\
2\end{array}$ & $\begin{array}{l}8.97 \mathrm{E}+0 \\
2 \\
\end{array}$ \\
\hline POCP & 1.3 & $\begin{array}{l}1.32 \mathrm{E} \\
-04\end{array}$ & $\begin{array}{l}2.11 \mathrm{E} \\
-04\end{array}$ & $\begin{array}{l}2.90 \mathrm{E} \\
-04\end{array}$ & $\begin{array}{l}2.37 \mathrm{E}- \\
02\end{array}$ & $\begin{array}{l}3.78 \mathrm{E}- \\
02\end{array}$ & $\begin{array}{l}6.12 \mathrm{E}- \\
02\end{array}$ & \begin{tabular}{|l}
$7.54 \mathrm{E}-$ \\
02 \\
\end{tabular} \\
\hline $\begin{array}{l}\text { Environmen } \\
\text { Unit }\end{array}$ & I & $\begin{array}{l}3.79 \mathrm{E} \\
-03\end{array}$ & $\begin{array}{l}6.07 \mathrm{E} \\
-03\end{array}$ & $\begin{array}{l}8.34 \mathrm{E} \\
-03\end{array}$ & $\begin{array}{l}2.84 \mathrm{E}+0 \\
2\end{array}$ & $\begin{array}{l}4.47 \mathrm{E}+0 \\
2\end{array}$ & $\begin{array}{l}7.30 \mathrm{E}+0 \\
2\end{array}$ & $\begin{array}{l}8.93 \mathrm{E}+0 \\
2\end{array}$ \\
\hline
\end{tabular}


Table 21: Weighted value based on estimated data for CNC

\begin{tabular}{|c|c|c|c|c|c|c|c|c|}
\hline \multirow{2}{*}{$\begin{array}{l}\text { Environmental } \\
\text { Impact }\end{array}$} & \multirow{2}{*}{$\begin{array}{l}\text { Weighting } \\
\text { Factor }\end{array}$} & \multicolumn{7}{|c|}{ Weighted Value of CNC process } \\
\hline & & $15 \mathrm{~mm}$ & $25 \mathrm{~mm}$ & $35 \mathrm{~mm}$ & $45 \mathrm{~mm}$ & $55 \mathrm{~mm}$ & $65 \mathrm{~mm}$ & $75 \mathrm{~mm}$ \\
\hline GWP & 1.1 & 0.00088 & $\begin{array}{l}1.63 \mathrm{E}- \\
03\end{array}$ & $\begin{array}{l}2.38 \mathrm{E}- \\
03\end{array}$ & $\begin{array}{l}3.14 \mathrm{E}- \\
03\end{array}$ & $\begin{array}{l}3.89 \mathrm{E}- \\
03\end{array}$ & $\begin{array}{l}4.65 \mathrm{E}- \\
03\end{array}$ & $\begin{array}{l}5.40 \mathrm{E}- \\
03\end{array}$ \\
\hline AP & 1.3 & $\begin{array}{l}8.80 \mathrm{E}- \\
04\end{array}$ & $\begin{array}{l}1.48 \mathrm{E}- \\
03\end{array}$ & $\begin{array}{l}2.07 \mathrm{E}- \\
03\end{array}$ & $\begin{array}{l}2.67 \mathrm{E}- \\
03\end{array}$ & $\begin{array}{l}3.27 \mathrm{E}- \\
03\end{array}$ & $\begin{array}{l}3.87 \mathrm{E}- \\
03\end{array}$ & $\begin{array}{l}4.46 \mathrm{E}- \\
03\end{array}$ \\
\hline EP & 1 & $\begin{array}{l}2.53 \mathrm{E}- \\
03\end{array}$ & $\begin{array}{l}1.74 \mathrm{E}- \\
03\end{array}$ & $\begin{array}{l}9.45 \mathrm{E}- \\
04\end{array}$ & $\begin{array}{l}1.55 \mathrm{E}- \\
04\end{array}$ & $\begin{array}{l}- \\
6.35 \mathrm{E}- \\
04\end{array}$ & $\begin{array}{l}- \\
1.43 \mathrm{E}- \\
03\end{array}$ & $\begin{array}{l}- \\
2.22 \mathrm{E}- \\
03\end{array}$ \\
\hline ODP & 63 & $\begin{array}{l}5.66 \mathrm{E}- \\
06\end{array}$ & $\begin{array}{l}7.77 \mathrm{E}- \\
06\end{array}$ & $\begin{array}{l}9.87 \mathrm{E}- \\
06\end{array}$ & $\begin{array}{l}1.20 \mathrm{E}- \\
05\end{array}$ & $\begin{array}{l}1.41 \mathrm{E}- \\
05\end{array}$ & $\begin{array}{l}1.62 \mathrm{E}- \\
05\end{array}$ & $\begin{array}{l}1.83 \mathrm{E}- \\
05\end{array}$ \\
\hline POCP & 1.3 & $\begin{array}{l}3.91 \mathrm{E}- \\
04\end{array}$ & $\begin{array}{l}5.41 \mathrm{E}- \\
04\end{array}$ & $\begin{array}{l}6.91 \mathrm{E}- \\
04\end{array}$ & $\begin{array}{l}8.40 \mathrm{E}- \\
04\end{array}$ & $\begin{array}{l}9.90 \mathrm{E}- \\
04\end{array}$ & $\begin{array}{l}1.14 \mathrm{E}- \\
03\end{array}$ & $\begin{array}{l}1.29 \mathrm{E}- \\
03\end{array}$ \\
\hline \multicolumn{2}{|c|}{ Environmental Load Unit } & $\begin{array}{l}4.68 \mathrm{E}- \\
03\end{array}$ & $\begin{array}{l}5.39 \mathrm{E}- \\
03\end{array}$ & $\begin{array}{l}6.10 \mathrm{E}- \\
03\end{array}$ & $\begin{array}{l}6.82 \mathrm{E}- \\
03\end{array}$ & $\begin{array}{l}7.53 \mathrm{E}- \\
03\end{array}$ & $\begin{array}{l}8.24 \mathrm{E}- \\
03\end{array}$ & $\begin{array}{l}8.96 \mathrm{E}- \\
03\end{array}$ \\
\hline
\end{tabular}

\section{4. $\underline{\text { Result and Discussion }}$}

After calculating the weighted value for both the processes a graph is made to illustrate the outcome and make a comparison between the two processes. In the illustration, DED is denoted with blue and $\mathrm{CNC}$ in red. The $\mathrm{X}$-axis shows the part complexity and the $\mathrm{Y}$-axis shows weighted environmental impact. The graph indicated that the slope is much steep for CNC than it is for DED. This indicated that with the increment of height, $\mathrm{CNC}$ has more impact on the environment than it is for the DED process. A trendline is drawn for both the processed to analyze the inclination of weighted environmental impact. For DED, the relation between environmental load unit and part complexity is found almost linear in this study. For CNC, the relation is also linear but, in this process, more data are out of the line than DED.

To find the sweet spot between DED and CNC the trendline is extended towards the centerline. The graph shows that, both the lines merge at $4 \mathrm{~mm}$ approximately. Which indicated that the environmental impact will be same in both DED and CNC process if a $4 \mathrm{~mm}$ turbine blade is manufactured. 


\section{Part Height Vs Weighted Environmental Impact}

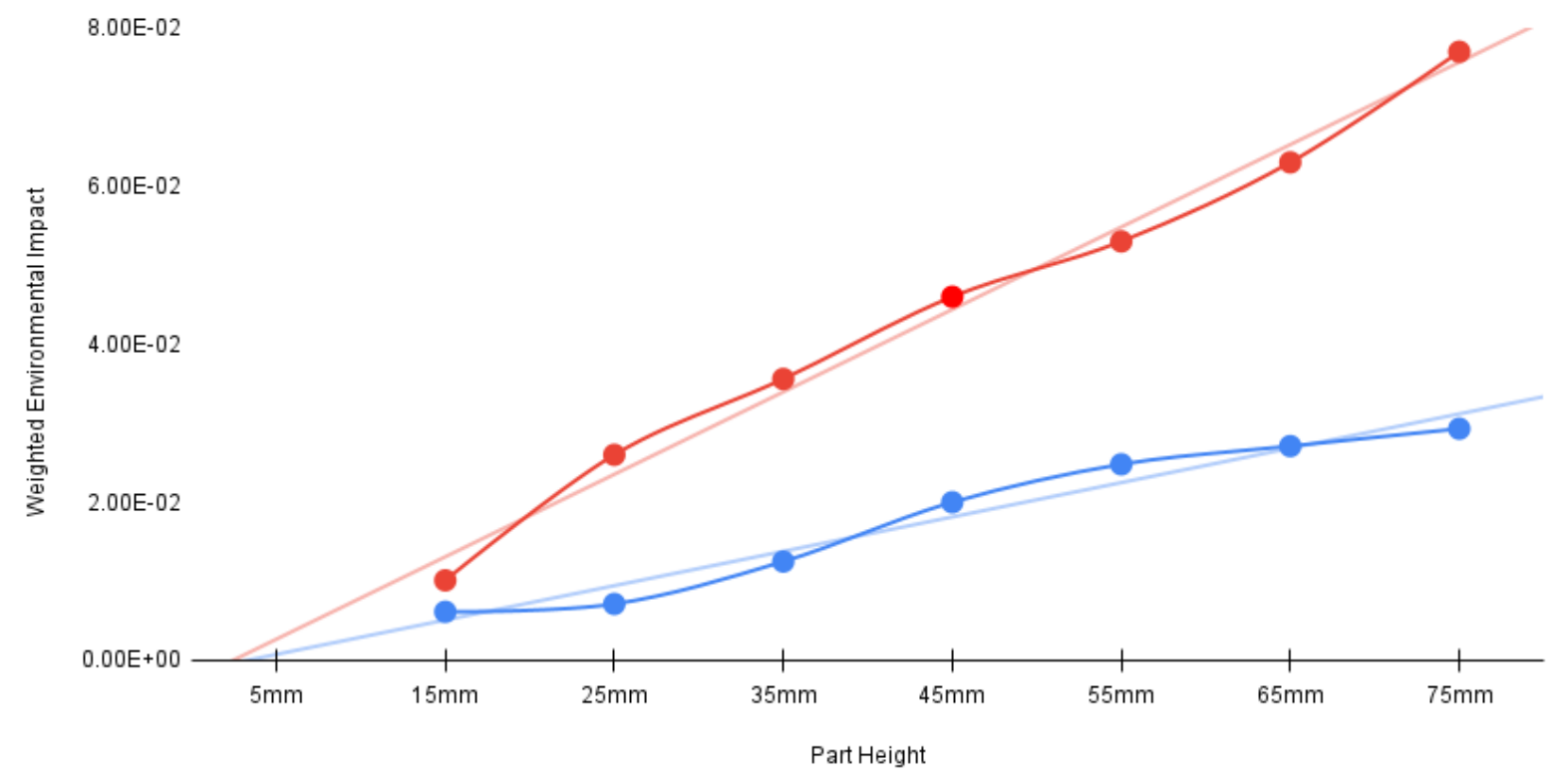

Figure 27: Part Complexity Vs Weighted Environmental Impact Comparison

Abiotic depletion refers to the depletion of nonliving (abiotic) resources such as fossil fuels, minerals, clay, and peat. As this impact category is different from the other substance emission indicators, the normalization and weighting references are not the same for this category. So, the result of ADP is separately compared using the characterized value for both experimental and estimated data.

Table 22: The characterized value of ADP (experimental and estimated)

\begin{tabular}{|l|l|l|l|l|l|l|l|}
\hline \multicolumn{7}{|c|}{ Characterized value } \\
\hline & $\mathbf{1 5} \mathbf{m m}$ & $\mathbf{2 5} \mathbf{m m}$ & $\mathbf{3 5} \mathbf{m m}$ & $\mathbf{4 5} \mathbf{m m}$ & $\mathbf{5 5} \mathbf{m m}$ & $\mathbf{6 5} \mathbf{m m}$ & $\mathbf{7 5} \mathbf{m m}$ \\
\hline DED & $1.11 \mathrm{E}+02$ & $1.78 \mathrm{E}+02$ & $2.45 \mathrm{E}+02$ & $3.12 \mathrm{E}+02$ & $3.79 \mathrm{E}+02$ & $4.46 \mathrm{E}+02$ & $5.13 \mathrm{E}+02$ \\
\hline CNC & $2.79 \mathrm{E}+02$ & $2.79 \mathrm{E}+02$ & $2.79 \mathrm{E}+02$ & $2.79 \mathrm{E}+02$ & $2.79 \mathrm{E}+02$ & $2.79 \mathrm{E}+02$ & $2.79 \mathrm{E}+02$ \\
\hline
\end{tabular}

The below graph shows the comparative position of DED and CNC based on the characterized ADP data points. 


\section{Comparison of ADP and part height}

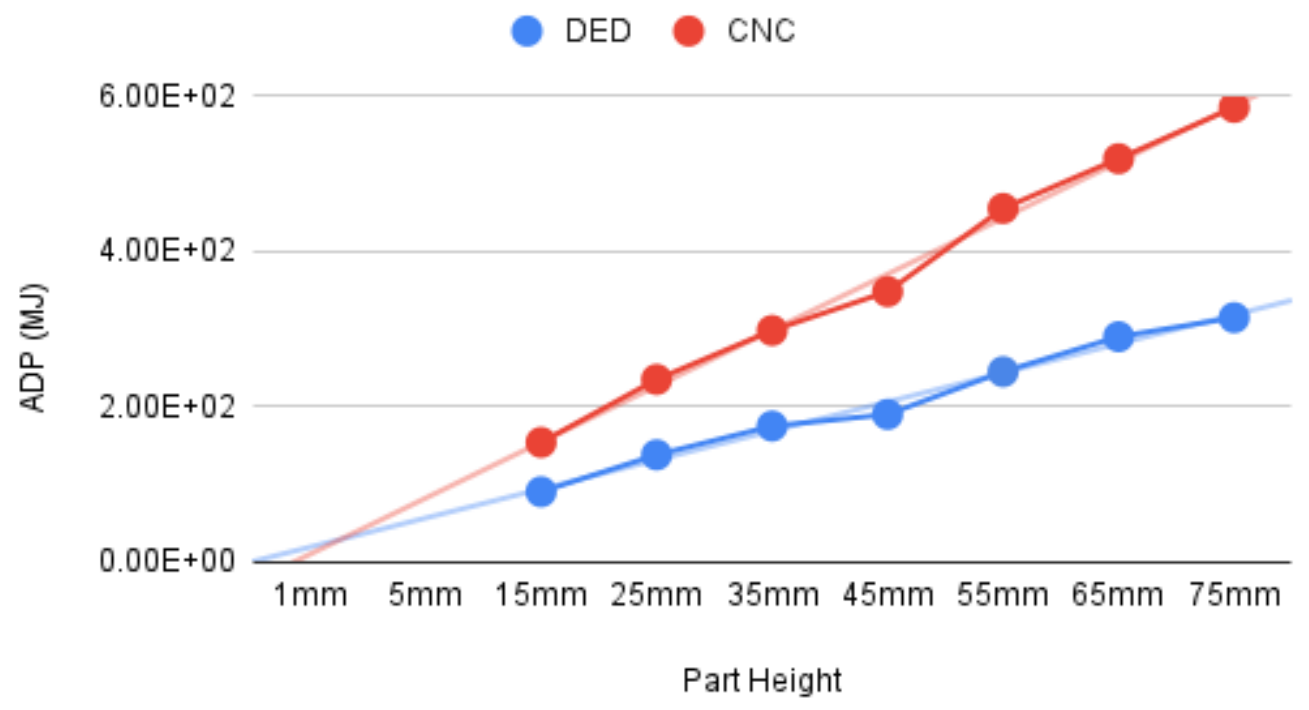

Figure 28: Part Complexity Vs ADP Comparison

For the lower value of part complexity, the impact is very close for both the process with $\mathrm{CNC}$ a bit higher than DED. As the complexity increased the impact also increased. But the slope of CNC is bigger than DED for the same complexity change which indicated that for the same change of part complexity, CNC has more ADP impact than DED. Considering only ADP value, the sweet spot between DED and CNC comes at $3 \mathrm{~mm}$ for this study. Which means if we make a $3 \mathrm{~mm}$ blade, the environmental impact considering ADP will be same for both the processes.

Quantitative evaluation of shape complexity of parts has been demonstrated, using geometrydriven criteria based on the number of cores, part volume ratio, core volume ratio, area ratio. Analysis of three turbine blade parts of varying complexity was successful in determining the coefficients of the shape complexity equation. The relation has been validated by proving its usefulness for the estimation of the shape complexity of new parts. The shape complexity equation can be employed in the early phases of the product life cycle, particularly in design for manufacturability, since it does not depend on process planning. The part designer can quickly estimate the shape complexity of a part (from its CAD model), allowing the comparison of alternate designs in terms of their influence on environmental impact.

Data collection is an essential step in LCA analysis, and the quality and accuracy of data should respond with the goal and scope definition and meet the expectations of the decision-makers. Due to the limitations of the machine, cost, and time, the blade fabrication through DED and CNC cannot realize batch production. Therefore, the discrepancy cannot be avoided. Once the production of blades realizes batch production in the future, the process-related data can be collected onsite, and the problem of discrepancy can be solved. In this process, it is assumed that the parts that are produced are meeting the level without doing any tensile, hardness, or any other 
material testing. In real life, every product will not meet the quality criteria and will be rejected for use. But these rejected products also produce an environmental impact. The quality issue can be an interesting topic for future study.

Also, the results of resource consumption and environmental impact are analyzed based on the condition that a single blade is studied and the blade size is relatively small. In reality, the turbine blade is made in batch, and the size is bigger than the object in this study. If a bigger blade is considered, the differences in the environmental impacts between DED and CNC process will become more obvious, because few materials will be removed in the milling process (Paris et al. 2016). The environmental impact will largely be affected by the energy consumed in the blade manufacturing processes.

\section{Conclusion}

In this study, the overall environmental performances of laser additive manufacturing and traditional manufacturing processes are figured out with LCA methodology for a case of turbine blade production. The final environmental impacts show that the blade laser fabrication generates fewer environmental impacts compared with its traditional manufacturing processes. Also, with the increment in part complexity, CNC produces more environmental impact than DED. For a $15 \mathrm{~mm}$ blade, CNC created $55.9 \%$ more environmental load unit than CNC while for a $25 \mathrm{~mm}$ blade, this impact is $62.9 \%$ higher. From the estimation data it is found that, for $35 \mathrm{~mm}, 45 \mathrm{~mm}$, $55 \mathrm{~mm}, 65 \mathrm{~mm}$, and $75 \mathrm{~mm}$ blades, CNC produces $64.9 \%, 65.3 \%, 66.5 \%, 67.7 \%$, and $71.2 \%$ more environmental load than CNC respectively.

In both the DED and traditional manufacturing processes, the environmental impact is largely determined by electric power and material consumptions. Due to the low powder efficiency in the DED process, a large amount of metal powder is lost during the deposition process and therefore, more materials are consumed to fabricate the blade. On the other hand, more materials needed to be removed during the $\mathrm{CNC}$ process, the specific energy consumption in $\mathrm{CNC}$ is higher than that of DED manufacturing of blade; therefore, more energy is needed in the entire CNC process compared with the additive manufacturing process.

For $15 \mathrm{~mm}$ and $25 \mathrm{~mm}$ blades, the complexity factor is calculated from the experimental value, and this, the value for $35 \mathrm{~mm}$ data is estimated. For $15 \mathrm{~mm}, 25 \mathrm{~mm}$, and $35 \mathrm{~mm}$ blades, the complexity factor is 29.82, 30.91, and 32.11 respectively. This shows that with the increment of part complexity, the complexity factor also increases and displays almost a linear relationship between them.

Additive manufacturing by direct energy deposition with metal powders is already very popular in industries because of its advantages including design freedom, high performance, and the ability to create parts with complex shapes. Now it is offering better performance even in environmental aspects. Though it is performing better compared with traditional manufacturing, it still is having a lot of environmental impacts. To promote its industrial development, some measures have to be taken to reduce its environmental impacts, such as increasing the powder efficiency. The results in this study can remind the environmental issues that existed in the DED process, and it can also 
be used in future work on an eco-efficiency decision while designing products from a life cycle perspective. 


\section{Reference:}

[1] Shitong Peng, Tao Li, Xinlin Wang, Mengmeng Dong, Zhichao Liu, Junli Shi, and Hongchao Zhang, Environmental Impact Comparison of Different Impeller Manufacturing Methods, School of Mechanical Engineering, Dalian University of Technology, Dalian, China Department of Industrial Engineering, Texas Tech University, Lubbock, TX, USA.

[2] Gasser A, Backes G, Kelbassa I, Weisheit A, Wissenbach K (2010). Laser additive manufacturing. Laser Technik J 7(2):58-63.

[3] Jeantette FP, Keicher DM, Romero JA, Schanwald LP (2000). U.S. Patent, No. 6,046,426. Washington, DC: U.S. Patent and Trademark Office.

[4] Pei YT, De Hosson JTM (2000). "Functionally graded materials produced by laser cladding". Acta Mater 48(10):2617-2624.

[5] Santos EC, Shiomi M, Osakada K, Laoui T (2006). "Rapid manufacturing of metal components by laser forming." Int J Mach Tools Manuf 46(12):1459-1468.

[6] Scott J, Gupta N, Weber C, Newsome S, Wohlers T, Caffrey T (2012). "Additive manufacturing: status and opportunities." Science and Technology Policy Institute, Washington, pp 1-29.

[7] U.S. Energy Information Administration, "International Energy Outlook 2013," http://www.eia.gov/forecasts/ieo/pdf/0484(2013).pdf (Accessed 17 February 2019).

[8] Tao Li, Jian Zhuang, Hong-chao Zhang, ZhiChao Liu. "Energy Consumption Assessment of Remanufacturing Processes". 20th CIRP International Conference on Life Cycle Engineering, Singapore, 2013.

[9] DebRoy, T.; Wei, H.L.; Zuback, J.S.; Mukherjee, T.; Elmer, J.W.; Milewski, J.O.; Beese, A.M.; Wilson-Heid, De, A.; Zhang, W. "Additive manufacturing of metallic components-Process, structure, and properties." Prog. Mater. Sci. 2018, 92, 112-224.

[10] Tanisha Pereira, John V Kennedy, Johan Potgieter. "A comparison of traditional manufacturing vs additive manufacturing, the best method for the job." 14th Global Congress on Manufacturing and Management (GCMM-2018).

[11] Henri Paris, Hossein Mokhtarian, Eric Coatane, Matthieu Museau, Inigo Flores Ituarte. "Comparative environmental impacts of additive and subtractive manufacturing technologies.” CIRP Annals - Manufacturing Technology 65 (2016) 29-32.

[12] Zhichao Liu, Qiuhong Jiang, Weilong Cong, Tao Li, Hong-Chao Zhang. "Comparative study for environmental performances of traditional manufacturing and directed energy deposition processes." Int. J. Environ. Sci. Technol. (2018) 15:2273-2282.

[13] Jeremy Faludi, Cindy Bayley, Suraj Bhogal, Myles Iribarne. "Comparing Environmental Impacts of Additive Manufacturing vs. Traditional Machining via LifeCycle Assessment." The University of California, Berkeley (2014).

[14] W.R. Morrow, H. Qi, I. Kim, J. Mazumder, S.J. Skerlos. "Environmental aspects of the laser-based and conventional tool and die manufacturing." Journal of Cleaner Production 15 (2007). 
[15] Zhichao Liu, Qiuhong Jiang, Tao Li, Shiyun Dong, Shixing Ya, Hongchao Zhang, Binshi Xu. "Environmental benefits of remanufacturing: A case study of cylinder heads remanufactured through laser cladding. " Journal of Cleaner Production 133 (2016).

[16] Mathias Burkharta, Jan C. Aurichb. "Framework to predict the environmental impact of additive manufacturing in the life cycle of a commercial vehicle." Procedia CIRP 29 (2015) $408-413$.

[17] Jeremy Faludi, Martin Baumers, Ian Maskery, and Richard Hague. "Environmental Impacts of Selective Laser Melting." Journal of Industrial Ecology Volume 21, 2016.

[18] Qiuhong Jiang, Tao Li, Zhichao Liu, Hongchao Zhang, Keda Ren. "Life Cycle Assessment of an Engine with Input-Output Based Hybrid Analysis Method." Journal of Cleaner Production 78 (2014) 131-138.

[19] Sangwon Suh, Gjalt Huppes. "Methods for Life Cycle Inventory of a product." Journal of Cleaner Production 13 (2005) 687-697.

[20] Adrita Dass, Atieh Moridi. "State of the Art in Directed Energy Deposition: From Additive Manufacturing to Materials Design." Coatings 2019, 9, 418.

[21] R. Sreenivasan, A. Goel, D.L. Bourell. "Sustainability issues in laser-based additive manufacturing." Physics Procedia 5 (2010) 81-90.

[22] Hae-Sung Yoon, Jang-Yeob Lee, Hyung-Soo Kim, Min-Soo Kim, Eun-Seob Kim, Yong-Jun Shin, Won-Shik Chu, and Sung-Hoon Ahn. "A Comparison of Energy Consumption in Bulk Forming, Subtractive, and Additive Processes: Review and Case Study." INTERNATIONAL JOURNAL OF PRECISION ENGINEERING AND MANUFACTURING-GREEN TECHNOLOGY Vol. 1, No. 3, pp. 261-279 (2014).

[23] Jeffrey B. Dahmus, Timothy G. Gutowski. "AN ENVIRONMENTAL ANALYSIS OF MACHINING." 2004 ASME International Mechanical Engineering Congress and RD\&D Expo.

[24] W.R. Morrow, H. Qi, I. Kim, J. Mazumder, S.J. Skerlos. "Environmental aspects of the laser-based and conventional tool and die manufacturing." Journal of Cleaner Production 15 (2007) 932-943.

[25] Daniel Bockin, Anne-Marie Tillman. "Environmental assessment of additive manufacturing in the automotive industry. " Journal of Cleaner Production 226 (2019) 977987.

[26] Fu Zhao, William Z. Bernstein, Gautam Naik, Gary J. Cheng. "Environmental assessment of laser-assisted manufacturing: case studies on laser shock peening and laserassisted turning." Journal of Cleaner Production 18 (2010) 1311-1319.

[27] Nicolas Serres, Dorian Tidu, Simon Sankare, Françoise Hlawka. "Environmental comparison of MESO-CLAD process and conventional machining implementing life cycle assessment". Journal of Cleaner Production 19 (2011) 1117-1124.

[28] Megan Kreiger, Joshua M. Pearce. "Environmental Life Cycle Analysis of Distributed Three-Dimensional Printing and Conventional Manufacturing of Polymer Products." ACS Sustainable Chem. Eng. 2013, 1, 1511-1519. 
[29] Tao Li, Zhi-Chao Liu, Hong-Chao Zhang, Qiu-Hong Jiang. "Environmental emissions and energy consumptions assessment of a diesel engine from the life cycle perspective." Journal of Cleaner Production 53 (2013) 7-12.

[30] Zhichao Liu, Tao Li, Qiuhong Jiang, Hongchao Zhang. "Life Cycle Assessmentbased Comparative Evaluation of Originally Manufactured and Remanufactured Diesel Engines." Journal of Industrial Ecology (2014) Vol 14.

[31] Harsha Malshe, Hari Nagarajan, Yayue Pan, Karl Haapala. "PROFILE OF SUSTAINABILITY IN ADDITIVE MANUFACTURING AND ENVIRONMENTAL ASSESSMENT OF A NOVEL STEREOLITHOGRAPHY PROCESS." ASME 2015 International Manufacturing Science and Engineering Conference.

[32] Simon Ford, Melanie Despeisse. "Additive manufacturing and sustainability: an exploratory study of the advantages and challenges." Centre for Technology Management, Institute for Manufacturing, University of Cambridge, CB3 OFS, United Kingdom, 2016.

[33] Mariano Jiménez, Luis Romero, Iris A. Dominguez, Maria del Mar Espinosa, Manuel Dominguez. "Additive Manufacturing Technologies: An Overview about 3D Printing Methods and Future Prospects" Hindawi Complexity Volume 2019, Article ID 9656938.

[34] Zhichao Liu, Hong-Chao Zhanga, Shitong Peng, Hoyeol Kima, Dongping Dua, Weilong Conga. "Analytical modeling and experimental validation of powder stream distribution during direct energy deposition." Additive Manufacturing 30 (2019) 100848.

[35] B. Subramanyam, T.V.Vineeta, Parthasarathy Garre, V.V.SNikhil Bharadwajj, P. Shiva Shashank, "Comparative Analysis of Additive Manufacturing over Conventional Manufacturing." Materials Science and Engineering 455 (2018).

[36] Mariano Jiménez,Luis Romero, Iris A. Domínguez, María del Mar Espinosa, Manuel Domínguez. "Additive Manufacturing Technologies: An Overview about 3D Printing Methods and Future Prospects." Complexity, Hindawi, vol. 2019, pages 1-30, February.

[37] Jeffrey B. Dahmus, Timothy G. Gutowski. "AN ENVIRONMENTAL ANALYSIS OF MACHINING.” IMECE2004 ASME International Mechanical Engineering Congress and RD\&D Expo.

[38] Durgesh Joshi, and Bhallamudi Ravi. "Quantifying the Shape Complexity of Cast Parts." Computer-Aided Design \& Applications, 7(5), 2010, 685-700.

[39] Guinee, J.B., Gorree, M., Heijungs, R., Huppes, G., Kleijn, R., de Koning, A., vanOers, L., Sleeswijk, A.W., Suh, S., Udo de Haes, H.A., de Bruijn, H., van Duin, R., Huijbregts, M.A.J., Lindeijer, E., Roorda, A.A.H., van der Ven, B.L., Weidema, B.P., 2002. "Handbook on Life Cycle Assessment: Operational Guide to the ISO Standards. Kluwer Academic Publishers, Dordrecht, Boston, London".

[40] Ibrahim Dincer, Azzam Abu-Rayash. Energy Sustainability 2020, Pages 119-164 Chapter 6 - Sustainability modeling 
[41] Guinée, J.B., Handbook on Life Cycle Assessment. Operational Guide to the ISO Standards. Kluwer Academic Publishers. 2004

[42] Kloepffer, W., Grahl, B. Life Cycle Assessment (LCA). A Guide to Best Practice. Wiley-VCH. 2014.

[43] Reap, J., Roman, F., Duncan, S., \& Bras, B. (2008). A survey of unresolved problems in life cycle assessment. The International Journal of Life Cycle Assessment, 13(5), 374-388.

[44] ISO - International Standard Organization (2006) Environmental management Life cycle assessment -Requirements and guidelines. ISO14044, Geneva

[45] Kim, J., Yang, Y., Bae, J., \& Suh, S. (2013). The importance of normalization references in interpreting life cycle assessment results. Journal of Industrial Ecology, 17(3), 385-395.

[46] Heijungs, R., Guinée, J., Kleijn, R., \& Rovers, V. (2007). Bias in normalization: causes, consequences, detection, and remedies. The International Journal of Life Cycle Assessment, 12(4), 211-216.

[47] Wenzel, H, M.Z. Hauschild \& L. Alting, 1997 Environmental assessment of products Vol.1. 544 pp. Chapman \& Hall, United Kingdom, Kluwer Academic Publishers, Hingham, MA. USA. ISBN 0412808005.

[48] Hauschild, M. and H. Wenzel, 1998. Environmental assessment of products. Vol.2 Scientific background, 565 pp. Chapman \& Hall, United Kingdom, Kluwer Academic Publishers, Hingham, MA. USA. ISBN 0412808102.

[49] Handbook of Solvents (Second Edition) Volume 1: Properties 2014, Pages 11-41, $43-49,51-72$

[50] Lauran van Oers, Jeroen B. Guinée \& Reinout Heijungs, Abiotic resource depletion potentials (ADPs) for elements revisited-updating ultimate reserve estimates and introducing time series for production data, The International Journal of Life Cycle Assessment volume 25, pages294-308 (2020).

[51] Paris H, Mokhtarian H, Coatane'a E, Museau M, Ituarte IF (2016) 'Comparative environmental impacts of additive and subtractive manufacturing technologies. CIRP Ann Manuf Technol 65:29-32

[52] Hyun-Taek Lee, Ji-Hyeon Song, Soo-Hong Min, Hye-Sung Lee, Ki-Young Song, Chong Nam Chu \& Sung-Hoon Ahn, 'Research Trends in Sustainable Manufacturing: A Review and Future Perspective based on Research Databases', International Journal of Precision Engineering and Manufacturing-Green Technology volume 6, pages 809-819 (2019)

[53] Das S, Beama JJ, Wohlert M, Bourell DL (1998), 'Direct laser freeform fabrication of high-performance metal components. Rapid Prototyp J 4(3):112-117 
[54] Mudge RP, Wald NR (2007,) Laser engineered net shaping advances additive manufacturing and repair. Weld J 86(1):44

[55] Murr LE, Gaytan SM, Ramirez DA, Martinez E, Hernandez J, Amato KN, Wicker RB (2012), Metal fabrication by additive manufacturing using laser and electron beam melting technologies. J Mater Sci Technol 28(1):1-14

[56] Duverlie, P. J.; Castelain, M.: Cost estimation during design step: parametric method versus case based reasoning method, International Journal of Advanced Manufacturing Technology, 15, 1999, 895-906.

[57] USEPA (U.S. Environmental Protection Agency). 2006. Life cycle assessment: Principles and practice. EPA 600/R-06/060. Cincinnati, OH, USA: National Risk Management Research Laboratory.

[58] R. Sreenivasan, A. Goel, D.L. Bourell, 'Sustainability issues in laser-based additive manufacturing,' The University of Texas at Austin, Laboratory for Freeform Fabrication, 1 University Station, MC C2200, Austin, Texas USA 78712.

[59] Bhardwaj, T.; Shukla, M.; Paul, C.P.; Bindra, K.S. 'Direct energy depositionlaser additive manufacturing of titanium-molybdenum alloy: Parametric studies, microstructure and mechanical properties. J. Alloy.'Compd. 2019, 787, 1238-1248.

[60] Ansari, M.; Mohamadizadeh, A.; Huang, Y.; Paserin, V.; Toyserkani, E. 'Laser directed energy deposition of water-atomized iron powder: Process optimization and microstructure of single-tracks. Opt. 'Laser Technol. 2019, 112, 485-493. 